Int. J. Dev. Biol. 52: 873-886 (2008)

doi: $10.1387 / \mathrm{ijdb} .082597 \mathrm{fm}$

\title{
Developmentally regulated expression of hemoglobin subunits in avascular tissues
}

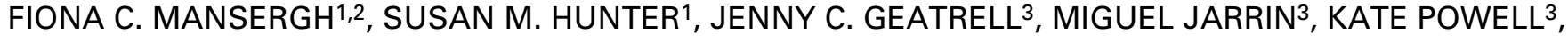 \\ MARTIN J. EVANS ${ }^{1}$ AND MICHAEL A. WRIDE $3,4, *$ \\ ${ }^{1}$ Cardiff School of Biosciences, Cardiff University, Wales, UK ${ }^{2}$ Smurfit Institute of Genetics, Trinity College Dublin, Ireland \\ ${ }^{3}$ School of Optometry and Vision Sciences, Cardiff University, Wales, UK and 4 Ocular Development and Neurobiology Research Group, \\ Department of Zoology, School of Natural Sciences, Trinity College Dublin, Ireland
}

\begin{abstract}
We investigated the spatio-temporal profile of hemoglobin subunit expression in developing avascular tissues. Significant up-regulation of hemoglobin subunits was identified in microarray experiments comparing blastocyst inner cell masses with undifferentiated embryonic stem (ES) cells. Hemoglobin expression changes were confirmed using embryoid bodies (derived from in vitro differentiation of ES cells) to model very early development at pre-vascular stages of embryogenesis; i.e. prior to hematopoiesis. We also demonstrate, using RT-PCR, Western blotting and immunocytochemistry, expression of adult and fetal mouse hemoglobin subunits in the avascular ocular lens at various stages of development and maturation. Hemoglobin proteins were expressed in lens epithelial cells (cytoplasmic) and cortical lens fiber cells (nuclear and cellsurface-associated); however, a sensitive heme assay demonstrated negligible levels of heme in the developing lens postnatally. Hemoglobin expression was also observed in the developing eye in corneal endothelium and retinal ganglion cells. Gut sections showed, in addition to erythrocytes, hemoglobin protein staining in rare, individual villus epithelial cells. These results suggest a paradigm shift: hemoglobin subunits are expressed in the avascular lens and cornea and in prehematopoietic embryos. It is likely, therefore, that hemoglobin subunits have novel developmental roles; the absence of the heme group from the lens would indicate that at least some of these functions may be independent of oxygen metabolism. The pattern of expression of hemoglobin subunits in the perinuclear region during lens fiber cell differentiation, when denucleation is taking place, may indicate involvement in the apoptosis-like signaling processes occurring in differentiating lens fiber cells.
\end{abstract}

KEY WORDS: hemoglobin, lens, differentiation, embryoid body, stem cell

\section{Introduction}

Globins, small globular heme-binding proteins, have been identified in bacteria, plants, fungi and animals, highlighting their ancient evolutionary origins (Garrocho-Villegas et al., 2007, Vinogradov etal., 2007). Four globin families, differing in structure and tissue distribution (hemoglobin, myoglobin, neuroglobin and cytoglobin) have been identified in vertebrates (Pesce et al., 2002, Hankeln et al., 2005). The major functions of hemoglobin pertain to oxygen transport, especially in the hematopoietic system. Moreover, evidence is emerging for hemoglobin expression outside the erythroid lineage. The first such reports demonstrated neuronal expression and suggested that iron-catalyzed oxidation of neuronal hemoglobin could have a role in motor neuron degeneration (Ohyagi and Goto, 1994, Ohyagi et al., 1994).

\footnotetext{
Abbreviations used in this paper: EB, embryoid body; Eraf, erythroid associate factor; ES, embryonic stem; GZ, lens germinative zone; ICM, inner cell mass; LEC, lens epithelial cell; LFC, lens fiber cell; LIF, leukemia inhibitory factor; mo, month; OD, optical density; OFZ, organelle free zone; p, postnatal; pc, post coitum; PCR, polymerase chain reaction; RGC, retinal ganglion cell; RPE, retinal pigment epithelium; trHbs truncated hemoglobins.
}

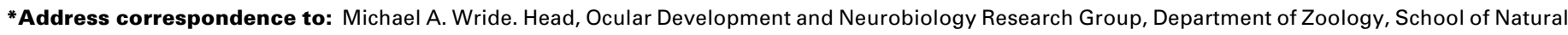
Sciences, Trinity College, Dublin, Dublin 2, Ireland. Tel: +353-1-896-1036. Fax: +353-1-677-8094. e-mail: wridem@tcd.ie Web: http://tcdlocalportal.tcd.ie/pls/public/staff.detail?p_unit=zoology\&p_name=wridem
}

Supplementary Material (six figures and a movie) for this paper is available online at: http://dx.doi.org/10.1387/ijdb.082597fm

Received: 29 January 2008; Evaluated: 28 February 2008; Accepted: 1 April 2008; Published online: 19 May 2008. 
Hemoglobin was also shown to be expressed in macrophages and alternative roles for it in oxygen or nitric oxide sensing were proposed (Liu et al., 1999). The results suggested that individual hemoglobin genes could be selectively expressed in various cell types (as opposed to blood, in which $\alpha$-and $\beta$-hemoglobin subunit expression is coordinated stoichiometrically in order to form the heme-containing, $2 \alpha, 2 \beta$ tetramers required for oxygen transport). Recently, expression of adult $\alpha$ - and $\beta$-hemoglobins has been noted in primate and rodent alveolar type II (ATII) cells (stem cells that differentiate into alveolar type I cells) and Clara cells (the primary producers of pulmonary surfactant), implying an important role for hemoglobin in lung physiology and possibly pathophysiology (Bhaskaran et al., 2005, Newton et al., 2006).

Suggested extra-hematopoietic roles for hemoglobins include detoxification of $\mathrm{NO}$, as $\mathrm{O}_{2}$-scavenging/sensing/consuming enzymes (Pesce et al., 2002) and in apoptosis in the absence of the heme moiety (Brecht et al., 2005a, Brecht et al., 2005b). Small cathepsin-mediated proteolytic cleavage products of hemoglobin proteins (hemorphins) have cytotoxic and anti-proliferative effects on cells and act as "atypical" opioid peptides (Fruitier et al., 1999, Blishchenko et al., 2002, lanzer et al., 2006). Finally, truncated hemoglobins (trHbs) are small hemoproteins (20-40 residues shorter than full-length mammalian hemoglobin chains found in bacteria, higher plants, and unicellular eukaryotes) that define a distinct phylogenetic group within the globin super-family (Nardini et al., 2007).

We became interested in avascular expression of hemoglobin subunits for two reasons. Firstly, microarrays were used to investigate gene expression differences between embryonic stem (ES) cells and the blastocyst inner cell masses (ICMs) from which ES cells are derived (Hunter et al., 2008)(GEO: GSE8881). The genes encoding the adult $\alpha$-hemoglobin and embryonic $\beta$-hemoglobin subunits (Hba-a1/2 and $\mathrm{Hbb}-\mathrm{Y}$ ) were significantly upregulated in ICMs at two different stages of development. As early embryos give insufficient material for protein studies (our array studies were carried out using mRNA derived from two rounds of amplification), here we used in vitro ES cell differentiation with embryoid bodies (EBs) to model early embryonic devel- opment and to investigate hemoglobin subunit expression prior to hematopoiesis. ES cells are pluripotent cells, which can contribute to all cell types of the embryo proper (Evans and Kaufman, 1981, Smith, 2001). EBs are floating aggregates of ES cells that, when grown without leukemia inhibitory factor (LIF), mimic the developmental potential of early-stage embryos, albeit in a disorganized way (Leahy et al., 1999, O'Shea, 2004). Precursors, representative of all three germ layers, are produced and directed differentiation can be used to yield specific cell types (Keller et al., 1993, Kennedy et al., 1997, Bain et al., 2000, Desbaillets et al., 2000, O'Shea, 2004).

Secondly, our gene expression profiling study (Wride et al., 2003) of wild type post-natal mouse lens maturation showed expression of embryonic and adult hemoglobin subunits (Hba-a1/ 2, Hba-X, Hbb-b1, Hbb-b2, and Hbb-Y) and a chaperone (erythroid associate factor; EraF/ $\alpha$-hemoglobin stabilizing protein; AHSP [ $\alpha$-hemoglobin stabilizing protein], which is involved in $\alpha$-hemoglobin folding). We went on to demonstrate that these genes are significantly downregulated in Sparc knockout mouse lenses during cataract progression (Mansergh et al., 2004). Other microarray studies revealed downregulation of the $\alpha$-hemoglobin gene in the human lens epithelium and in the mimecan null mouse lens during cataract progression (Hawse et al., 2003, Tasheva et al., 2004).

The lens is an excellent model system for studies of development, maturation and aging (Lovicu and Robinson, 2004). It consists of an outer layer of lens epithelial cells (LECs), which contain a stem cell niche centrally and anteriorly (Zhou et al., 2006), while peripheral LECs proliferate, migrate and differentiate into lens fiber cells (LFCs), a process that begins during embryogenesis and continues throughout life (Griep, 2006). Therefore, a cross section of a lens at any age reveals a spectrum of cells in various stages of quiescence, proliferation and differentiation. Lens transparency requires removal of LFC nuclei and organelles during differentiation, resulting in formation of an organelle free zone (OFZ). Components of apoptosis signaling and proteolytic pathways are utilized in this process (Bassnett, 2002, Wride, 2007); defects can cause lens opacity or cataract (Pendergrass et
A

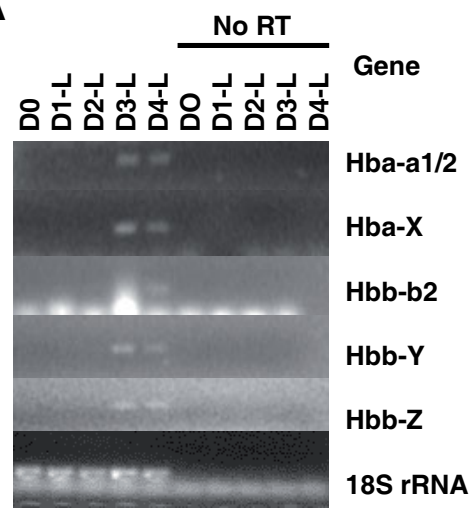

B

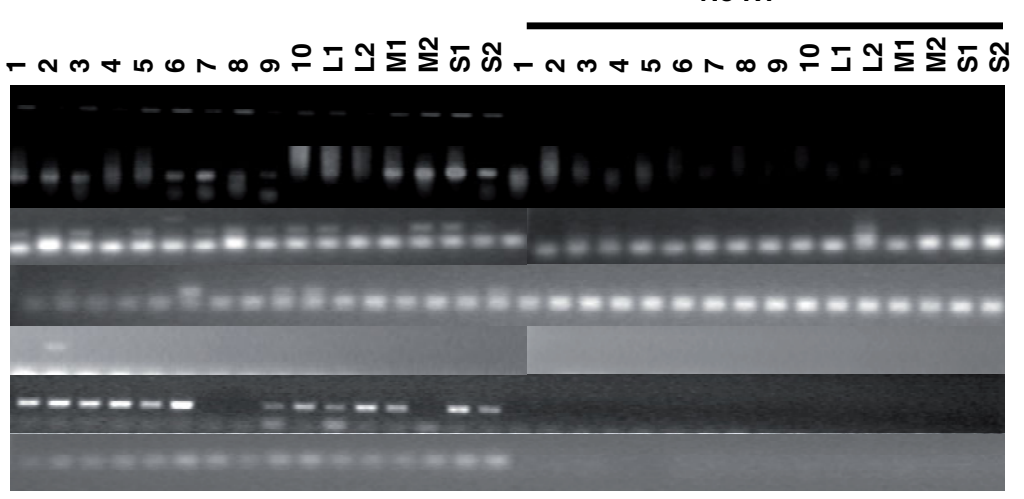

Gene

Hba-a1/2

Hbb-b1

Hbb-b2

KDR

Brachyury

Hprt

18S rRNA

Fig. 1. Semi-quantitative RT-PCR of hemoglobins during early EB differentiation in cultures -LIF. (A) Unamplified RNA from EB culture, 1000 cells/hanging drop, -LIF. DO (Day 0), undifferentiated ES cells; D1 (Day 1) etc. PCR conditions used (gene: cycles, annealing temp): Hba-a1/2: 30, 58; Hba-X: 32, 61; Hbb-b2: 40, 61; Hbb-Y: 32, 61; Hbb-Z: 40, 58; 18sRNA: 22, 63). (B) Amplification of RNA from individual EBs, day 4 (D4)-LIF. L, large; $M$, medium; S, small EBs. KDR = early erythropoietic marker, Brachyury = early mesodermal marker, Hprt = alternative loading control giving variable results (as do actin and Gapdh; data not shown). PCR conditions used (gene: cycles, annealing temp): Hba-a1/2: 40, 58; Hbb-b1: 40, 61; KDR: 59, 45; Brachyury: 55, 40; Hprt: 58, 32; 18s RNA: 26, 62). 18s RNA = loading control. No-RT controls were run for each sample. 
al., 2005). LFCs, erythrocytes, blood platelets and keratinocytes are the only cell types that lose nuclei and organelles during terminal differentiation (Lockshin and Zakeri, 2004). Notably, the lens is entirely avascular and can be dissected free of hematopoietic contamination, potentially making it an ideal model system for the study of hemoglobin subunit function outside of the hematopoietic system (Wride et al., 2003, Mansergh et al., 2004).

Here, we present a thorough spatio-temporal analysis of embryonic and adult $\alpha$ - and $\beta$-hemoglobin subunit expression during early embryonic development, early ES cell differentiation and mouse lens development. The expression of hemoglobin protein subunits in pre-vascular embryos and in an avascular tissue (the lens), suggests a paradigm shift. In addition to the accepted function of hemoglobin in hematopoietic oxygen transport, we postulate developmental roles for hemoglobin in apoptosis signaling and/or early development and stem cell differentiation. These results pave the way for functional studies to determine the developmental roles of hemoglobin subunits outside the hematopoietic system.

\section{Results}

\section{ES cell-embryo microarrays and EB RT-PCR}

Microarray studies, comparing individually picked undifferentiated ES cell colonies with various microdissected ICM stages from which ES cells are derived, revealed differential expression of hemoglobin between blastocyst ICMs at 88 and $105 \mathrm{~h}$ post coitum (pc) and undifferentiated ES cells. Fold changes were as follows: Hbb-Y (mean of 3 different spots): $+3.29(P=0.0014)$ and Hba-a1/ 2 (mean of 2 different spots): +3.21 mean $(p=0.00065)$. The entire MIAME compliant dataset has been submitted to and approved by GEO (http://www.ncbi.nlm.nih.gov/geo/; series accession number GSE8881). Given the paucity of starting material, two rounds of RNA amplification were required prior to arraying. Amplification can lead to bias in results; in order to minimize this, amplification and arraying methods were exhaustively optimized. These studies are described comprehensively elsewhere (Hunter et al., 2008). Genes known to be involved in ES cell pluripotency and early development were also noted as differentially regulated in other results obtained from this array study (GSE8881), suggesting a high level of accuracy.

Nevertheless, we have attempted to confirm the reliability of these results using the reverse transcriptase-polymerase chain reaction (RT-PCR). Unamplified RNA from pooled ICMs can be used for RT-PCR if the genes in question are expressed at levels similar to $\beta$-actin, Gapdh or 18S rRNA (Hunter et al., 2008); however, less abundantly expressed RNAs, such as the globin genes, are undetectable. We have detected adult hemoglobin subunits using one round of amplification with single EBs prior to RT-PCR with 40 cycles (see below). However, these EBs had an initial cell number of 1000 and could have contained up to 16,000 cells by day 4 , as ES cells double roughly every 24 hours. ICMs 88 hours pc contain 48 cells; even $15-20$ pooled ICMs would have given a total cell number of under 1000. PCR using double amplified RNA gives very erroneous results as the length of individual RNAs is reduced to 200-400bp on average and is very 3 ' biased. Moreover, sufficient material for protein studies cannot be obtained with ease. We therefore asked the question as to whether hemoglobins are expressed during undirected early in

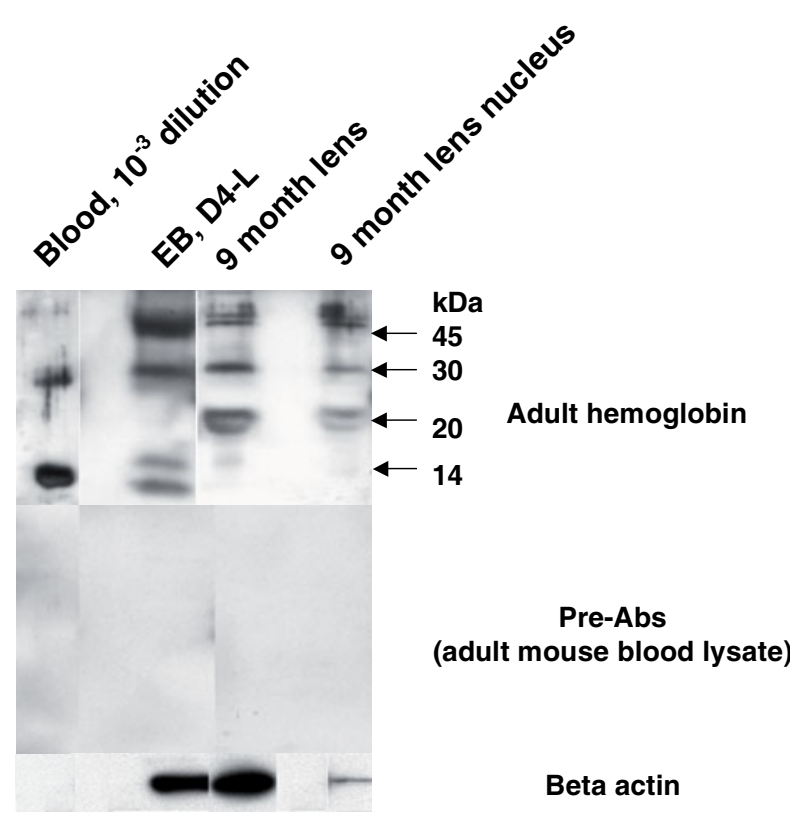

Fig. 2. Western blotting of hemoglobins during early EB differentiation day 4 EB-LIF compared to adult lens lysates. Mouse blood lysate was used as positive control. $\beta$-actin was used as a loading control following stripping of blots. $\beta$-actin was not detectable in blood lysate as we used a $10^{-3}$ dilution of blood (approximately $0.024 \mu \mathrm{g}$ ) in order not to overload the gel. The blood blot gave a similar banding pattern as seen in the lens samples, with major bands at $14 \mathrm{kDa}$ (corresponding to $\alpha$-and $\beta$-globin monomers of $10 \mathrm{kDa}$ and $16 \mathrm{kDa}$ ) and $30 \mathrm{kDa}$ (corresponding to either alpha-globin trimers (30 kDa) and/or beta-globin dimers; see also Figure 5). In addition, there was a fainter band at approximately $45 \mathrm{kDa}$. The EB blot was similar to the blood blot except that there were two bands at around $14 \mathrm{kDa}$. These bands were much fainter in the 9 month lens samples (particularly the lens nucleus sample). The doublet band in both lens samples at approximately $20 \mathrm{kDa}$ was not present in the day 4 EB (-LIF) samples. Blots were stripped and re-probed with anti-hemoglobin antibody pre-absorbed with either blood lysate or human haemoglobin powder (data not shown), which completely abolished staining.

vitro differentiation of ES cells. EBs, with an initial cell number of 1000 , were grown in suspension for four days after the initiation of differentiation via formation of hanging drops and withdrawal of LIF from the culture medium. RNA was extracted from ES cells and from day 1-4 -LIF EBs and subjected to RT -PCR. Given the sequence similarity between genes within the $\alpha$-and $\beta$-hemoglobin gene clusters, expression of all hemoglobin genes was tested. No bands were identified at day 0 (undifferentiated ES cells), but expression of Hba-a1/2, Hba-X, Hbb-b2, Hbb-Y and Hbb-Z appeared at day 3 of culture and was maintained on day 4 (Fig. 1A). Expression of $\mathrm{Hbb}-\mathrm{b} 1$ was not detected; notably, other studies (see discussion) have referred to adult $\beta$-hemoglobin without differentiating between the two adult $\beta$-hemoglobin genes (Hbb-b1, Hbbb2), which are identical in sequence at the protein, but not mRNA level.

Given results suggesting expression of hemoglobin protein in each EB by immunofluorescence (see below), we tested whether the corresponding mRNAs were also expressed in each individual $E B$, as many genes upregulated in early development are only expressed in a minority of EBs at day 4 (e.g. Brachyury, Kdr, Afp, 
Goosecoid; Fib 7B and FCM, SMH and MJE, unpublished results). To ensure that immunocytochemical staining of all EBs (see below) was not non-specific (even given the lack of staining in IgG controls), we used one round of amplification to amplify RNA from 16 individual EBs. Hba-a1/2 was consistently expressed in each $E B$, regardless of its size, and was more consistently expressed than any other gene tested (including the early hematopoietic marker KDR, the mesodermal marker Brachyury and the housekeeping gene Hprt (Fig. 1B) as well as actin and Gapdh; data not shown); only 18S rRNA showed more consistent expression across all samples at day 4-LIF (Fig. 1B). Expression of both Hbbb1 and $\mathrm{Hbb}-\mathrm{b} 2$ was more variable (each being expressed in 10 out of 16 individual EBs; 62.5\%). Embryonic hemoglobin subunits ( $\mathrm{Hba}-\mathrm{X}, \mathrm{Hbb}-\mathrm{Y}$ and $\mathrm{Hbb}-\mathrm{Z}$ ) were not detectable in individual EBs using this method. This may simply be because they are expressed in a minority of EBs (i.e. none of those tested). However, this is more likely to be a result of the difficulties of PCR from low starting quantities of RNA; even one round of amplification shortens the length of most amplified mRNA (aRNA) fragments making PCR correspondingly more difficult, especially if primer sets are designed towards the 5' end of genes. We often have to increase PCRs by at least 6-8 cycles when using RNA generated from 1
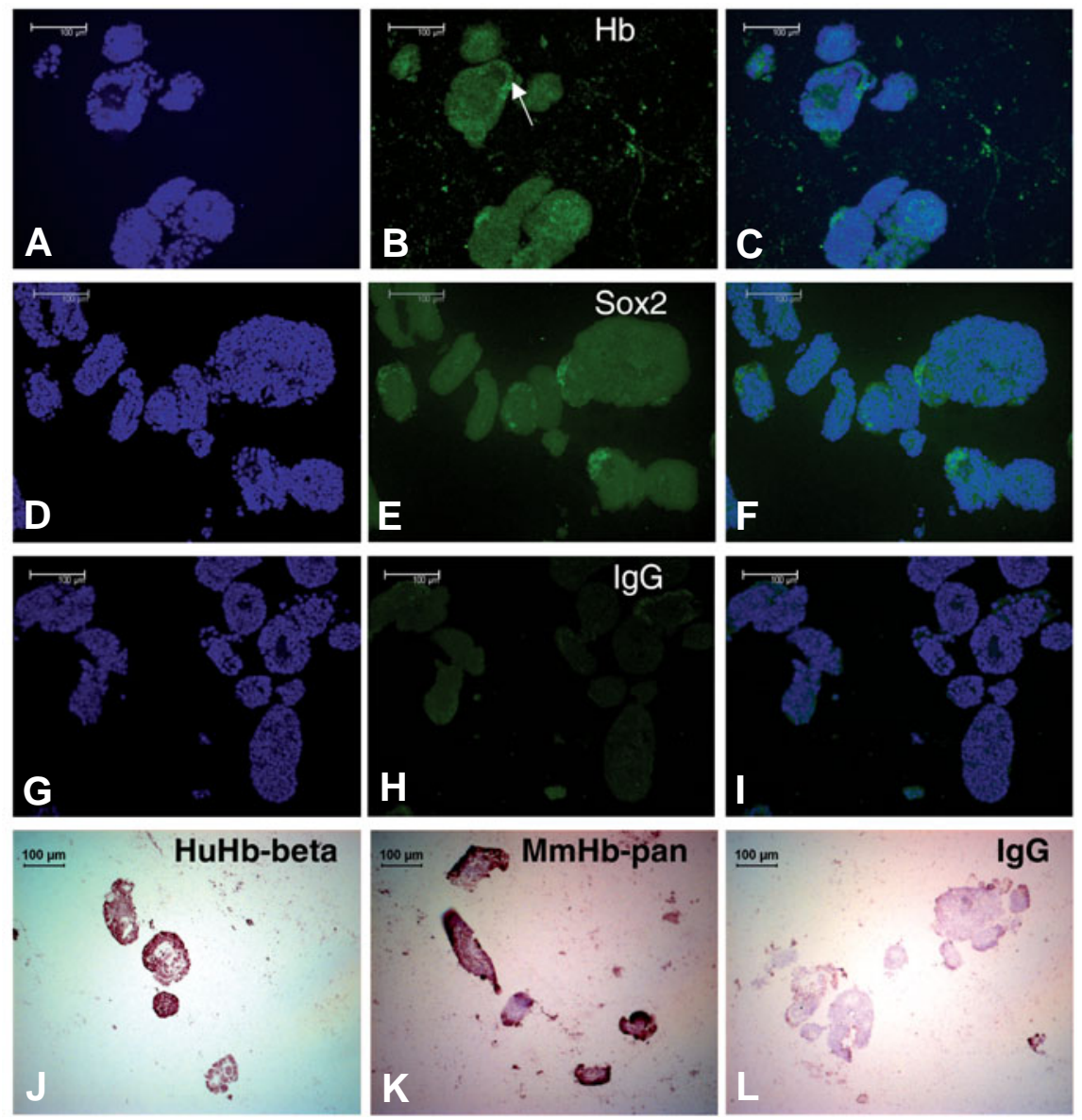

Fig. 3. Immunostaining of early differentiating EBs in culture. (A-I) Immunofluorescence and $\mathbf{( J - L ) ~ i m m u n o p e r o x i d a s e ~ f o r ~ h e m o g l o b i n ~}(\mathbf{B}, \mathbf{J}, \mathbf{K})$ and a positive control, Sox2 (E,F). Anti-mouse pan hemoglobin was used in B, $C$ and $K$, while anti-human $\beta$-hemoglobin was used in J. Hemoglobin staining was associated with the cytoplasm of nearly all cells in the $E B$, but not the nuclei (arrow in $B)$. $(\mathbf{H}, \mathbf{I}, \mathbf{L})$ Sections stained with rabbit $\lg G$ at the same concentration as the hemoglobin antibody are negative for staining. Bars, $100 \mu \mathrm{M}$. round of amplification. Moreover, the number of cycles required does not always relate well to cycles used for unamplified RNA , SMH and MJE, unpublished results), which may explain also why Hbb-b1 appears to be expressed when the RNA is

\section{Western blotting of hemoglobin proteins during early EB ifferentiation}

Western blotting was used to investigate hemoglobin protein expression in differentiating EBs at day 4 -LIF using the rabbit antimouse antibody to pan-mouse hemoglobins (ICN/Cappel; Fig. 2), nucleus. The blood blot gave a similar banding pattern as seen in the lens samples (see Fig. 5). In addition, there was a faint band at aproximately $45 \mathrm{kDa}$. The EB blot was similar to the blood blot with (n) 4 EBs -LIF. Blots were stripped and

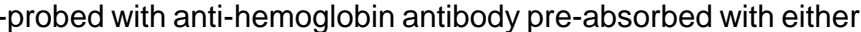
blood lysate or human hemoglobin powder (data not shown), which g. In the blood lysate blot, no $\beta$-actin band was obtained at the exposure times used, since we used blood lysate at a $10^{-3}$ dilution (approximately $0.024 \mu \mathrm{g}$ ) in order not to overload the gel; hemoglobin is readily detectable at these concentrations as it comprises $98 \%$ of RBC protein and is the largest protein constituent of blood; so, actin is below the level of detection.

\section{Immunofluorescence and immunoperoxidase for hemoglobin during early EB differentia- tion}

Immunofluorescence was carried out on day 4 -LIF EBs using the polyclonal antibody to mouse hemoglobin and an antibody to human $\beta$-hemoglobin (Fig. 3). Using the anti-mouse antibody with immunofluorescence, expression was observed in the cytoplasm of the majority of cells in the EBs (Fig. 3 B, C). An antibody to Sox2 was used as a positive control; this was localized to distinct regions of the EBs (Fig. $3 \mathrm{E}, \mathrm{F}$ ). Immunoperoxidase was also used to reveal staining for hemoglobin in early stage EB differentiation (Fig. $3 \mathrm{~J}-\mathrm{K}$ ); both the anti-mouse and antihuman antibodies revealed staining in EBs. The rabbit IgG controls were negative using both methods (Fig. $3 \mathrm{H}, \mathrm{I}$ ).

\section{Semi-quantitative RT-PCR of hemoglobins in the developing lens and cornea}

Previous results demonstrated expression of 5 of 6 hemoglobin subunit mRNAs in newborn, p7, p14 and 9 mo adult mice (Wride et al., 2003, Mansergh et al., 2004). Here, we show expression of all 6 adult and embryonic hemoglobin subunit mRNAs in the embryonic eye (E12.5) and lens (E14.5, E16.5, NB, p7, p14, and 4 wk; Fig. $4 \mathrm{~A})$. Hba-a1/2 had a fairly constant profile of 
expression, with a slight reduction in expression in the lens from newborn (NB) to 4 wks. The other hemoglobin chains and Ahsp/Eraf exhibited largely decreasing expression levels towards maturity (although $\mathrm{Hba}-\mathrm{x}$ and $\mathrm{Hbb}-\mathrm{y}$ both showed a slight peak of expression at day 7 , after an initial postnatal drop). Hbb-Z is expressed in the embryonic eye and lens at E12.5 and E14.5, but not subsequently. PCR cycles used reflect high expression of these genes at embryonic stages; use of higher cycles reveals more substantial expression at postnatal stages (Wride et al., 2003, Mansergh et al., 2004). The corneas of 9 mo wild type and Sparc knockout mice showed expression of Hba-a1 and $\mathrm{Hbb}-\mathrm{b} 2$ (adult hemoglobin subunits, Fig. 4B). Both $\mathrm{Hba}-\mathrm{a} 1 \mathrm{and} \mathrm{Hbb}-\mathrm{b} 2$ were significantly upregulated in Sparc knockout mouse corneas (Fig. 4B).

\section{Western blotting of hemoglobins in post-natal and adult lens lysates}

Western blotting revealed hemoglobin protein expression in the lens from newborn (NB) to 9 mo using a rabbit anti-mouse antibody to pan-mouse hemoglobin (ICN/Cappel). A monoclonal antibody to human fetal hemoglobin (AbCam cat\# ab20517-250) was used to investigate embryonic and fetal hemoglobin expression in the 9 mo mouse lens (Fig. 5). We also attempted Western blotting with 3 anti-human antibodies, none of which worked (immunocytochemical staining with these antibodies was faint). In all Western blots, $\beta$-actin was used as a loading control, while blood lysate was used as a positive control

Two major bands were detected on the blood blot at $14 \mathrm{kDa}$ and $30 \mathrm{kDa}$ (Fig. 5A). In the NB to p14 lens samples, bands were observed at $26 \mathrm{kDa}$ and $30 \mathrm{kDa}$. In the $4 \mathrm{wk}$ lens, the $26 \mathrm{kDa}$ band disappeared. In the 9 mo whole lens, the $30 \mathrm{kDa}$ band predominated. Also in the 9 mo lens, bands were present at $20 \mathrm{kDa}$ and $45 \mathrm{kDa}$. The $45 \mathrm{kDa}$ band and the upper band of the doublet at $20 \mathrm{kDa}$ were fainter in the 9 mo lens nucleus sample. Blots were stripped and re-probed with anti-hemoglobin antibody pre-absorbed with blood lysate or human hemoglobin powder and most staining was abolished. Blots were stripped and re-probed with $\beta$ actin, confirming equal protein loading. $\beta$-actin was not detectable in blood lysate at $10^{-3}$ dilution (approx $0.024 \mu \mathrm{g}$ ) because blood comprises $98 \%$ hemoglobin; therefore, actin is below levels for detection. Using the antibody to fetal hemoglobin on individual 9 mo lens lysates, bands were observed at $20 \mathrm{kDa}$ and $14 \mathrm{kDa}$ (Fig. 5B).

\section{Immunofluorescence for hemoglobin during lens, cornea and retina development and maturation}

\section{Embryonic day 16.5 (ED16.5) and NB}

Hemoglobin protein expression in the NB lens (Fig. 6 A-F) was detected in the LFCs in the cortex and was more intense in the anterior LFCs, compared to the posterior LFCs; it was faint in the cytoplasm of LECs. Staining was reduced towards the core of the lens, in which nuclei and other organelles are degenerating to form the OFZ. Intense staining was observed in erythrocytes associated with the hyaloid vasculature (Fig. 6 B, E, H; arrows). Staining was

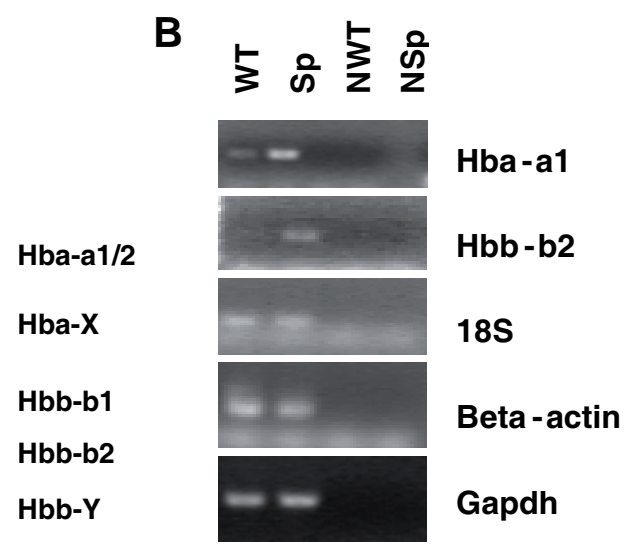

Hbb-Z

EraF

Gapdh

Fig. 4. Semi-quantitative RT-PCR of hemoglobins in the developing lens and the cornea. (A) $E 12.5$ eye $=$ embryonic day 12 eye; E14.5, E16.5, NB p7, p14, 4 wk = embry-
adult chains 1 and 2 were assessed together (Hba-a1/2) as Hba-a1 and Hba-a2 are identical in sequence. Hemoglobin, $\beta$ adult major chain $=H b b-b 1$, hemoglobin, $\beta$ adult minor chain $=H b b-b 2$. Hemoglobin $X$, embryonic chain $=H b a-X$; hemoglobin $Y, \beta$-like embryonic chain $=H b b-Y$ and (129 Sv/Ev). 18s rRNA, $\beta$-actin and Gapdh loading controls. NWT, NSp $=$ no RT controls. PCR conditions used in $A$ and $B$ (gene: cycles, annealing temp): Hba-a1/2: 32, 58; Hba-X: 32, 61; Hbb-b1: 32, 61; Hbb-b2: 32,

also associated with retinal ganglion cells (RGCs), the retinal pigment epithelium (RPE; Fig. $6 \mathrm{G}-\mathrm{I}$ ) and the corneal endothelium (CE; Fig. 6E). The rabbit IgG control was negative (Fig. $6 \mathrm{~J}-\mathrm{L}$ ). These data were similar to the staining observed in the eye of the ED16.5 embryo (Supplementary Fig. 1).

\section{P7 and p14}

Hemoglobin immunofluorescence was very intense in lens cortex LFCs that have not yet lost their nuclei (as indicated by 4',6diamidino-2-phenylindole (DAPI) staining) in both coronal (Fig. 7 A-F) and transverse (Fig. 7 G-O) sections, but was much less intense in the OFZ. Staining was also associated with the cytoplasm/cell surfaces of LECs, but not the nuclei (Fig. 7E and K). The RGC layer, other areas within the inner neuroblast layer (INBL), the corneal endothelium (CE) and the lens capsule (LC) were also positive. The rabbit IgG control was negative (Fig. $7 \mathrm{M}-\mathrm{O}$ ). Staining patterns in the p14 lens were similar to those at p7 (Supplementary Figs. 2,3).

\section{$4 w k s, 9 w k s$ and 9 mo}

In the 9 wk mouse lens, immunofluorescence was associated with cortical LFCs, particularly the border zone (BZ; Fig. 8 B-C), but, most-strikingly, it was associated with a peri-nuclear compartment and/or the nuclear membrane of cortical LFC nuclei (Fig. $8 \mathrm{E}$, $\mathrm{H}, \mathrm{F}$, and $\mathrm{I}$ ). A laser scanning confocal microscope movie illustrates this (Supplementary Movie 1; http://dx.doi.org/10.1387/ ijdb.082597fm). Nuclear-associated staining was significantly reduced in nuclei positioned further towards the anterior and core of the lens (arrowheads; Fig. 8C). A different plane of focus demon- 
strated hemoglobin immunofluorescence in LECs (Fig. 8K and L). Staining was associated with the cytoplasm of LECs in the germinative zone (GZ), but became localized to nuclei at the lens equator (EQ) in which LECs migrate, stop proliferating and begin their terminal differentiating into LFCs. The rabbit IgG control was negative (Fig. 4 M-O). 4 wk (Supplementary Fig. 4) and 9 mo (Supplementary Fig. 5) lenses showed similar staining patterns. At 4 wks and 9 wks, hemoglobin immunofluorescence was associated with the surfaces of posterior cortical LFCs (Fgure $4 \mathrm{H}$ and I; Supplementary Fig. 4 A-D). However, this pattern of immunofluorescence was different between 4 wks and 9 wks (compare Fig. 4B and 4D).

\section{Diaminofluorene heme assay reveals presence of heme in EBs,} but not in the lens

A diaminofluorene assay (Kaiho and Mizuno, 1985) was used to investigate whether heme was present in both lens and EB samples. A colorimetric heme assay using blood lysates at various dilutions $\left(10^{-4}, 10^{-5}\right.$ and $\left.10^{-6}\right)$ as positive controls and water as a negative control, was used to test various lens and EB homogenates (Fig. 9; Table 1). Calculating the mean of all values at 30 s and $45 \mathrm{~s}$ for each condition revealed statistically significant differences for blood lysates at dilutions of $10^{-4}$ and $10^{-5}$ (but not $10^{-6}$ ) compared to the water blank (see Table 1). The optical density (OD) was not significantly different to the water blank in any of the lens lysates. However, the level of heme in EBs was intermediate between the blood lysate samples diluted $10^{-4}$ and $10^{-5}(p=0.0016$, Table 1$)$.

We also used the diaminofluorene reaction as an histological stain for heme on tissue sections and on whole lenses (Supplementary Fig. 6). Positive staining (blue/green) was noted in the E16.5 embryo;
TABLE 1

\section{STATISTICAL ANALYSIS OF HEME ASSAY DATA PRESENTED IN FIG. 9}

\begin{tabular}{llc} 
t-test & p value & $\mathbf{n}$ \\
\hline blank vs blood $\times 10-4$ & $0.0000011^{*}$ & $\mathrm{n}=6$ \\
blank vs blood $\times 10-5$ & $0.0000006^{*}$ & $\mathrm{n}=6$ \\
blank vs blood $\times 10-6$ & 0,442809 & $\mathrm{n}=6$ \\
blank vs 9m lens & 0,414334 & $\mathrm{n}=7$ \\
blank vs post natal lens & 0,350203 & $\mathrm{n}=4$ \\
blank vs EB & $0.0015942^{*}$ & $\mathrm{n}=3$ \\
\hline
\end{tabular}

Using the un-paired students' t-test, significant differences are revealed in the heme assay between the water blank and blood lysates at $10^{-4}$ and $10^{-5}$ dilutions and between the water blank and EBs, but not between the water blank and blood lysate at $10^{-6}$ and the water blank and postnatal or 9 mo mouse lens lysates. Mean of values compared at $1 \mathrm{~min}$ and $1 \mathrm{~min} 30 \mathrm{~s}$.

there was positive staining for heme in the eye, including the lens and the retina (Supplementary Fig. 6 I-J). However, there was no detectable heme staining in sections of lenses from NB to p14, or in whole 9 mo lenses after 15 minutes in reaction mixture (Supplementary Fig. 6 E-F). However, in 9 mo corneas, a blue reaction color had developed afer 15 minutes owing to the presence of erythrocytes in the attached iris material (arrow in Supplementary Fig. 6H). EBs showed a low level of staining reflecting the levels of heme identified in EBs using the colorimetric heme assay (Fig. 9).

\section{Immunofluorescence for hemoglobin in adult mouse gut villus epithelium}

The gut is richly supplied with blood and, as such, represents a "normal" vascularized tissue and a positive control for hemoglobin
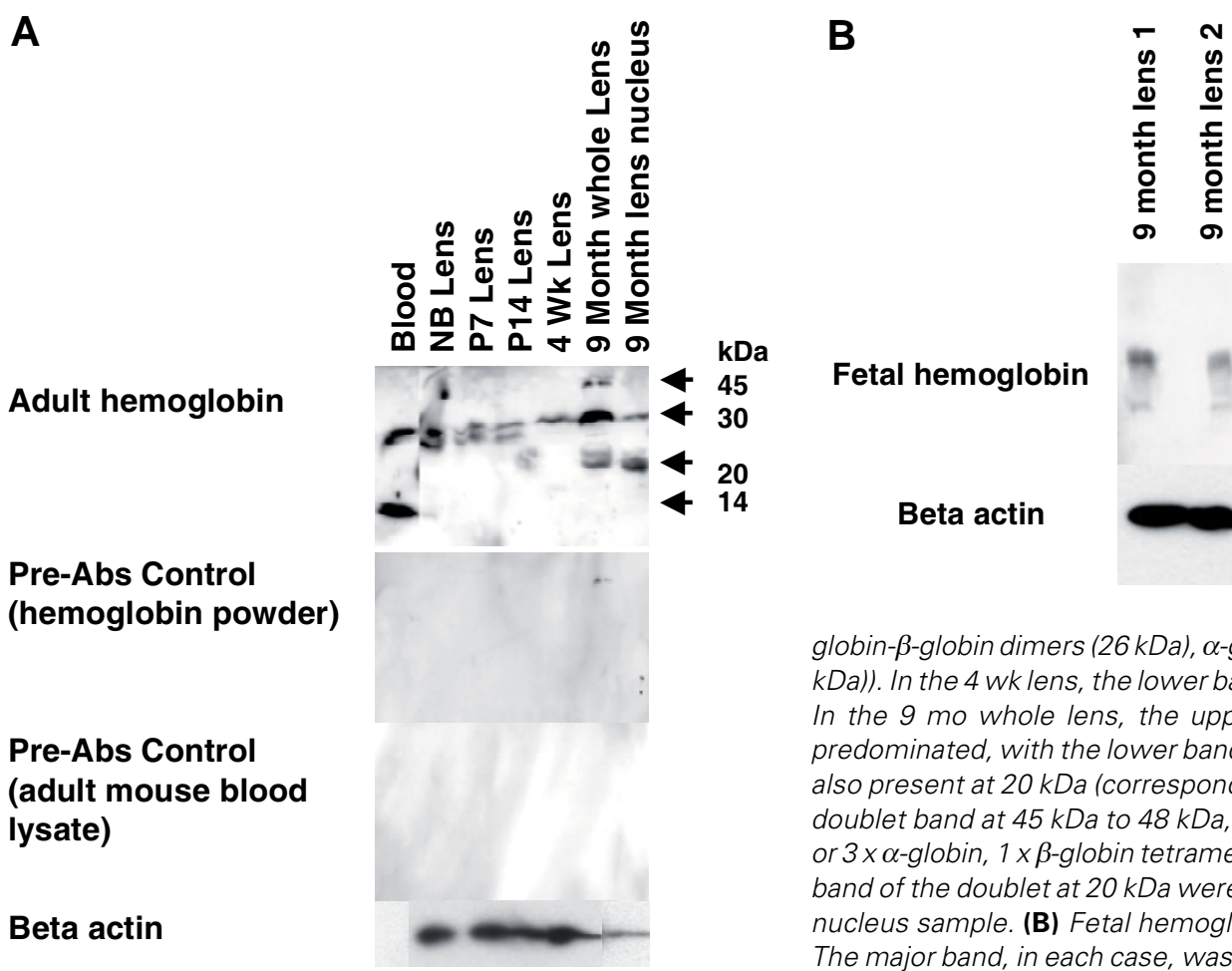

Fetal hemoglobin

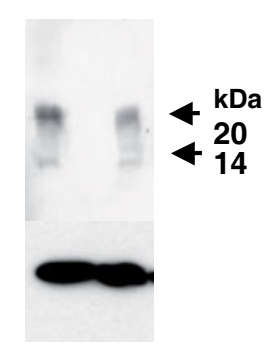

Beta actin

Fig. 5. Western blotting of hemoglobins in post-natal and adult lens lysates. (A) Mouse blood lysate was used as a positive control. Two major bands were detected in blood, one at approximately 14 kDa (corresponding to $\alpha$-and $\beta$-globin monomers of $10 \mathrm{kDa}$ and $16 \mathrm{kDa}$ ) and 30 $k D a$ (corresponding to either alpha-globin trimers and/or betaglobin dimers). In the NB to p14 lens samples, two bands were observed at approximately $26 \mathrm{kDa}$ and $30 \mathrm{kDa}$ (corresponding to $\alpha$ globin- $\beta$-globin dimers (26 kDa), $\alpha$-globin trimers (30 kDa) and/or $\beta$-globin dimers $(32$ $k D a))$. In the 4 wk lens, the lower band of the doublet at around $30 \mathrm{kDa}$ disappeared. In the 9 mo whole lens, the upper of the two bands at approximately $30 \mathrm{kDa}$ predominated, with the lower band very faint. In the 9 mo lens, a doublet band was also present at $20 \mathrm{kDa}$ (corresponding to $\alpha$-globin dimers). In addition, there was a doublet band at $45 \mathrm{kDa}$ to $48 \mathrm{kDa}$, corresponding to $\beta$-globin trimers ( $48 \mathrm{kDa}$ ) and/ or $3 \times \alpha$-globin, $1 \times \beta$-globin tetramers ( $46 \mathrm{kDa}$ ). The 45 to $48 \mathrm{kDa}$ band and the upper band of the doublet at $20 \mathrm{kDa}$ were reduced in intensity compared to the 9 mo lens nucleus sample. (B) Fetal hemoglobin expression in two 9 mo old mouse lenses. The major band, in each case, was at $20 \mathrm{kDa}$ (corresponding to fetal-globin dimers) with a fainter band at $14 \mathrm{kDa}$ (corresponding to fetal-globin monomers). Blots were stripped and re-probed with anti-hemoglobin pre-absorbed (Pre-Abs) with either blood lysate or human hemoglobin powder and this abolished staining (one representative blot shown). Blots were also stripped and re-probed with $\beta$-actin antibody to confirm equal protein loading. $\beta$-actin was not detectable in blood lysate as we used a $10^{-3}$ dilution (approximately $0.024 \mu \mathrm{g}$ ) of our original blood lysate in order not to overload the gel. 

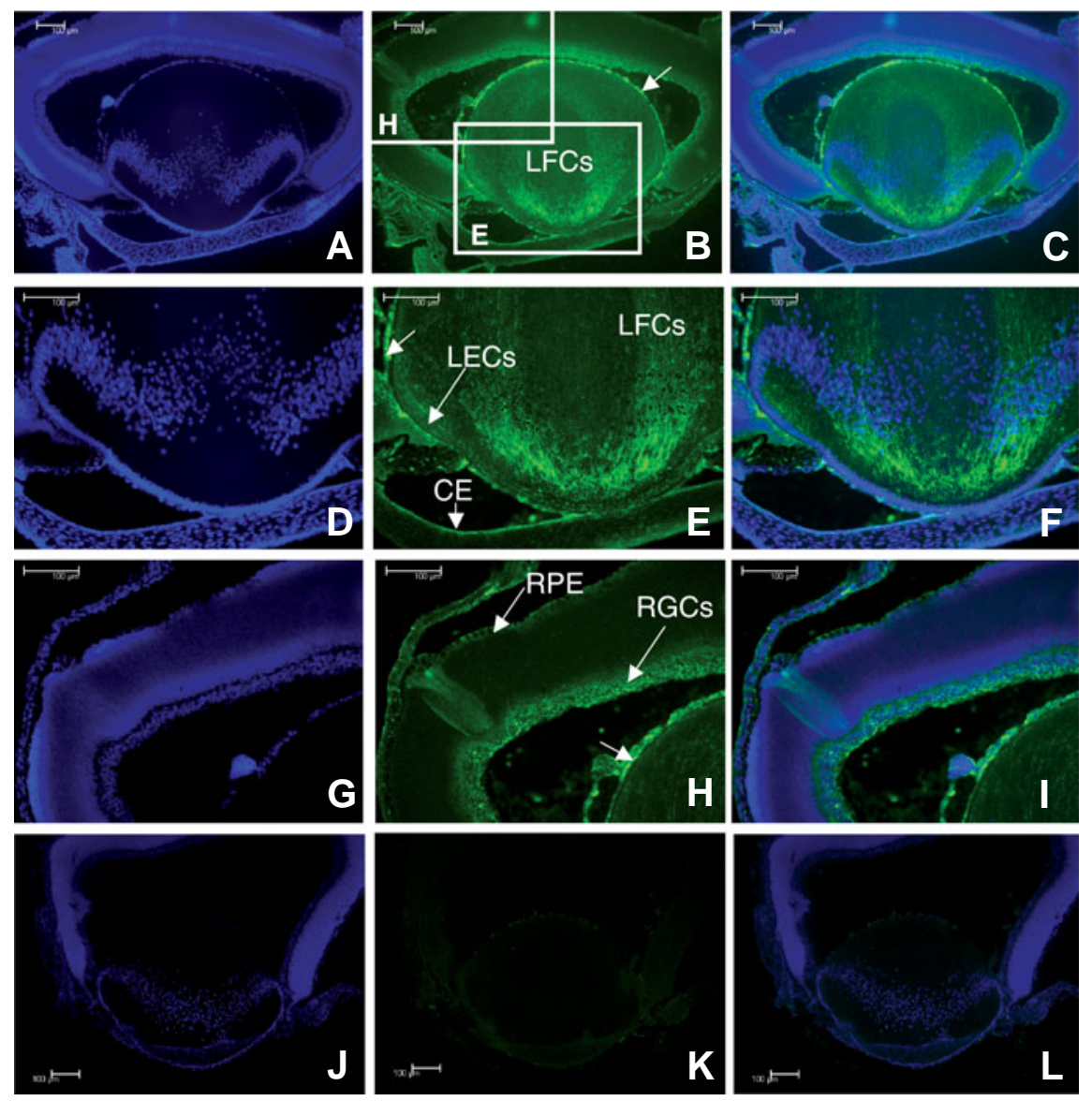

Fig. 6. Immunofluorescence for hemoglobin, newborn (NB) mouse eye. (A-J) DAPI labelling. (B-K) Hemoglobin immunofluorescence. (C-L) Merged images. Regions defined by white rectangles in $B$ are those in $E$ and $H$. Intense immunofluorescence for the lens caspule and/or erythrocytes can be seen at the back of the lens (arrows in $B, E, H$ ). Staining is intense in the anterior region of the LFCS, decreasing in a gradient towards the posterior of the lens, whereas staning is faint in the cytopasm of $L E C S$ (E). In the retina, staining is mainly associated with the developing RGC layer (H). RPE cells are also positive for staining as is the corneal endothelium (CE) (H). (J-L) Sections stained with rabbit Ig $G$ at the same concentration as the hemoglobin antibody are negative for staining. Bars, $100 \mu \mathrm{M}$.

immunofluorescence. Furthermore, since our evidence above suggested expression of hemoglobin in differentiation of stem cells in both LECs and EBs, we sought to investigate whether hemoglobin immunofluorescence was associated with gut villi, which contain stem cells in their crypts that migrate within villi epithelia and subsequently undergo terminal differentiation (Yen and Wright, 2006, Barker et al., 2007). In addition to erythrocytes (identified by positive staining for hemoglobin and lack of DAPI staining, since their nuclei have disappeared; arrowheads, Fig. $10 \mathrm{~A}-\mathrm{C}$ ), we identified a small, but significant number of hemoglobin positive cells at various positions within villus epithelia, excluding the crypts (Fig. $10 \mathrm{~A}-\mathrm{I}$, arrows).

\section{Discussion}

\section{Hemoglobin subunit expression in early embryos and EBs prior to hematopoiesis}

Our array results (GEO, GSE8881) demonstrated the expression of Hba-a1 and Hbb-y RNAs in the blastocyst ICM prior to implantation, a stage which can give rise to multipotent ES cells and is relatively undifferentiated. We have also shown hemoglobin subunit expression in EBs (a model of early differentiation) at stages several days prior to the accepted time of erythroid differentiation and blood island formation, in accordance with previously published work (Schmitt et al., 1991, Keller et al., 1993, Baird et al., 2001). However, we have demonstrated expression of a larger number of hemoglobin subunits than previously examined and hemoglobin protein subunit expression was also shown using immunofluorescence and Western blotting.

EBs have long been used for hematopoietic differentiation in vitro. Many groups have noted early expression of hemoglobin RNAs in EBs during initiation of hematopoietic differentiation protocols. Despite large variations in the starting size of the EBs (1-1000 cells), tissue culture media and detection methods (RT-PCR, RNase protection assay, subtractive library sequencing, staining for $\alpha$-hemoglobin protein), hemoglobin subunits are expressed consistently from day 3-5 of differentiation (Schmitt et al., 1991, Wiles and Keller, 1991, Keller et al., 1993, Baird et al., 2001). Variations in onset of expression are most likely related to the varying sensitivities of the assays. Our study, using RT-PCR on single EBs (with RNA amplification), revealed expression of the adult $\alpha$-hemoglobin gene in every single EB studied, suggesting an important role for it in early EB differentiation.

Hematopoietic stem cell differentiation studies tend to interpret the early expression of hemoglobin subunits as a sign of 'pre-conditioning' for the hematopoietic lineage. Further differentiation does indeed lead to hematopoietic specification and subsequent appearance of blood islands within the EBs, as well as primitive blast colonies that can be used to generate hematopoietic cells in vitro, and, to some extent, in vivo (Schmitt et al., 1991, Wiles and Keller, 1991, Keller et al., 1993, Kennedy et al., 1997, Baird et al., 2001). However, there are some differences between these prior studies and our results presented here. We show here that hemoglobins (in the previous studies associated with terminal erythropoiesis) are up-regulated simultaneously with Gata-1, a transcription factor involved in very early hematopoietic specification (Keller et al., 1993) and Brachyury, a very early marker of mesodermal differentiation. Moreover, we show that both KDR, a marker of early hematopoiesis (Ziegler et al., 1999) and Brachyury are expressed very inconsistently between individual EBs at day 4 -LIF (Fig. 1B), significantly more inconsistently than adult hemoglobin subunits (Hba1/2, Hbb-b1 and Hbb-b2). Hemoglobin subunit expression initiates 3-4 days prior to the obvious appearance of blood islands in the EBs (day 7 to 8 -LIF)(Keller et al., 1993). Moreover, in the embryo, the first signs of yolk sac hematopoiesis also appear at embryonic day 8 (Lindenbaum and Grosveld, 1990). Therefore, the timing of obvious hematopoietic differentiation is remarkably 

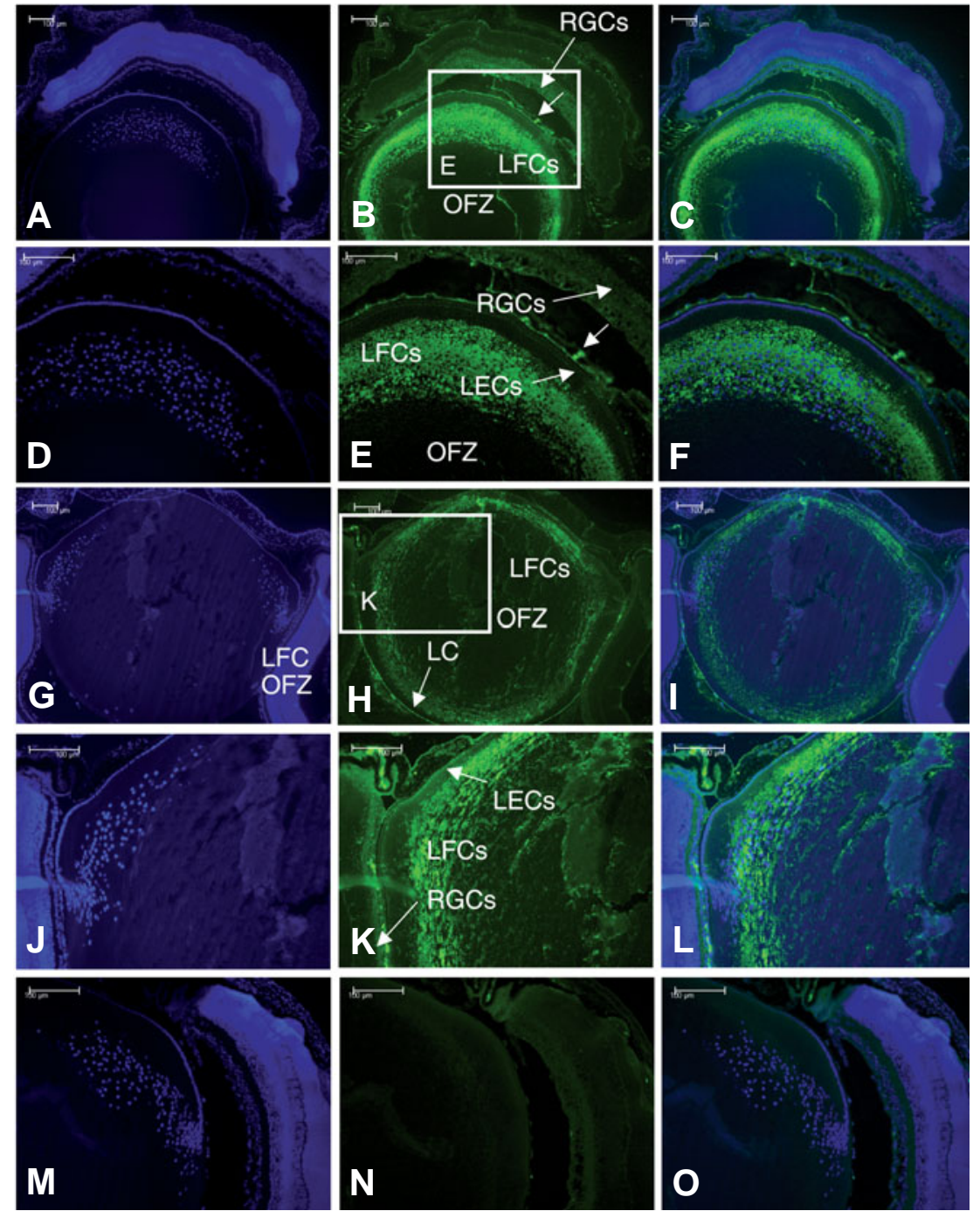

Fig. 7. Immunofluorescence for hemoglobin proteins, p7 mouse eye. (A,D,G,J,M) DAPI labelling. (B,E, $\mathbf{H}, \mathbf{K}, \mathbf{N})$ Hemoglobin immunofluorescence. (C, $\mathbf{F}, \mathbf{I}, \mathbf{L}, \mathbf{O})$ Merged im ages. (A-F) Coronal section through the eye. (G-O) Transverse section through the eye. Regions defined by white rectangles in $(B)$ and $(H)$ are those in $(E)$ and $(K)$. Intense immunofluorescence for erythrocytes and/or the lens capsule can be seen at the surface of the lens associated with the vitreous (arrows in B, E). Intense staining is observed in LFCs in the lens cortex in the layer in which lens fiber cells still retain their nuclei (B-K), but not significantly in LECS (K) or the OFZ (B-N). Immunofluorescence is also associated with the lens capsule $(L C)(\mathbf{H})$. In the retina, staining is associated with the RGC layer $(\mathbf{H})$. (M-O) Sections stained with rabbit IgG at the same concentration as the hemoglobin antibody are negative for staining. Bars, $100 \mu \mathrm{M}$.

similar in embryos and in EBs (day 8). In contrast, our arrays show up-regulation of $\mathrm{Hba}-\mathrm{a} 1 \mathrm{and} \mathrm{Hbb}-\mathrm{Y}$ in the undifferentiated ICM at $88 \mathrm{~h}$ and $105 \mathrm{~h} \mathrm{pc}$ (3.5-4.5 days). Furthermore, the expression of hemoglobin subunits appears at a stage when both embryos and EBs are showing very early signs of differentiation (day 3-4), rather than hematopoiesis per se. Notably, the ability of ES cell-derived hematopoietic precursors to reconstitute hematopoiesis in vivo is "surprisingly low" (Hole, 1999) or requires forced expression of the BCR/ABL oncogene (Perlingeiro et al., 2001) or HoxB4 (Kyba et al., 2002).

While it is possible that hemoglobin subunits may be specifying early hematopoietic 'pre-conditioning' (Baird et al., 2001), we propose, given that we have found them to be expressed in avascular tissues during development: in the $G Z$ of the lens epithelium and during differentiation of LFCs as well as in the cornea, that it is more likely that hemoglobin subunits have a more general role in the differentiation (or 'preconditioning') of numerous lineages during early embryonic development.

\section{Hemoglobin subunit expression in the lens}

Here, and in our previous studies, we have demonstrated hemoglobin subunit RNA and protein expression in prenatal and postnatal lenses and their down-regulation during cataract progression (Wride et al., 2003, Mansergh etal., 2004). During development, the lens is provided with oxygen and nutrients by the hyaloid vasculature, a structure removed by programmed cell death between $\mathrm{p} 12$ and $\mathrm{p} 16$ in the mouse (Ito and Yoshioka, 1999). The mature lens receives nutrients and removes waste products through the aqueous and vitreous humors without direct recourse to the vascular system. The expression of hemoglobin subunits in the lens is, therefore, suggestive of a new role for these proteins.

Notably, cataract and other ocular pathologies, including RPE degeneration, have been observed in association with sickle cell anemia and both $\alpha$ - and $\beta$-thalassemias (Bloomfield etal., 1978, Lorenzen et al., 1979, Gartaganis et al., 1989, Sorcinelli et al., 1990, Babalola et al., 2000, Athanasiadis et al., 2007). In the majority of these studies, the ocular anomalies observed have been attributed to iron metabolism disturbances. However, Babalola et al. (2000) described hereditary congenital cataracts associated with sickle cell anemia, while Lorenzen etal. (1979) found an association between sickle cell anemia and senile cataracts. It should also be pointed out that neither sickle cell anemia nor major thalassemias result in total loss of hemoglobin function. Therefore, it may be the case that expression of mutated $\beta$-hemoglobin (sickle cell disease), or 2 adult $\alpha$ - or $\beta$-hemoglobin subunit genes instead of 4 (thalassemia) is still sufficient to carry out any nonhematopoietic functions of the hemoglobin subunits and that pathology in these diseases is due entirely to hematopoietic insufficiency. However, given our results, it is possible that at least some of the ocular and/or systemic pathologies observed in sickle cell anemia and thalassemias may result from a diminution of non-hematopoietic functions of hemoglobin subunits and this possibility merits further analysis.

The immunofluorescence expression patterns we observe are consistent with roles for hemoglobin subunits in primary (ED16.5) and secondary LFC differentiation. Secondary lens fiber differentiation in the mouse peaks postnatally (p1-p7), correlating with increased hemoglobin subunit expression at p7. This process continues throughout life as new LFCs differentiate from LECs at the equator region of the lens. Furthermore, adult central LECs can 
be considered to be stem cells that divide very infrequently in normal circumstances, while their progeny, more peripheral LECs, provide limited proliferative potential and move into the $G Z$ towards the lens equator where they begin to cycle actively and to differentiate into LFCs (Zhou et al., 2006). Hemoglobin proteins are expressed in the cytoplasm of LECs of the GZ (Fig. 8B, K (9 wks) and Supplementary Fig. $5 ; 9$ mos). As these cells move towards the lens $E Q$, they acquire nuclear-associated expression of hemoglobin protein, which persists in cortical LFCs. There is prior evidence of nuclear cytoglobin expression (Geuens et al., 2003). Moreover, nuclear expression of a non-symbiotic plant hemoglobin is increased during hypoxia (Seregelyes et al., 2000). Notably, the nuclear association that we observe in the lens occurs spatially in shells of LFCs just outside those in which loss of LFC nuclei and organelles is occurring to form the OFZ during terminal LFC differentiation. The significance of immunofluorescence at the surface of LFCs (Fig. 8H and I; Supplementary Fig. 4) remains to be determined.

Since the heme moiety is undetectable in the lens from NB stages onwards, our prior hypotheses that hemoglobin subunits function as oxygen transporters, oxygen sinks or in iron homeostasis in the lens now seem unlikely (Wride et al., 2003, Mansergh et al., 2004). Therefore, given their expression patterns, the most credible hypothesis now is that hemoglobin subunits expressed in the lens are involved in aspects of LEC differentiation, specifically the denucleation/organelle loss undergone by maturing LFCs. This process appears to require components of apoptosis signaling pathways (Bassnett, 2002, Wride, 2007). Furthermore, Gata-2-mediated upregulation of $\alpha$-globin (i.e. $\alpha$-hemoglobin protein without the association of the heme moiety) is proapoptotic in hematopoietic and non-hematopoietic cell lines (Brecht et al., 2005a, Brecht et al., 2005b), acting through suppression of bcl-2, activation of bax, release of cytochrome $c$ and activation of caspases. Erythrocytes in most mammals undergo a loss of nuclei during erythroblast differentiation, albeit by enucleation (extrusion of the nucleus), rather than by denucleation (degradation of the nucleus). This process occurs concomitantly with hemoglobin up-regulation in erythroblasts (Koury et al., 1987). Furthermore, a number of erythroid differentiation denucleation factors (EDDFs) have been identified (Xue et al., 2006). It will be interesting to investigate
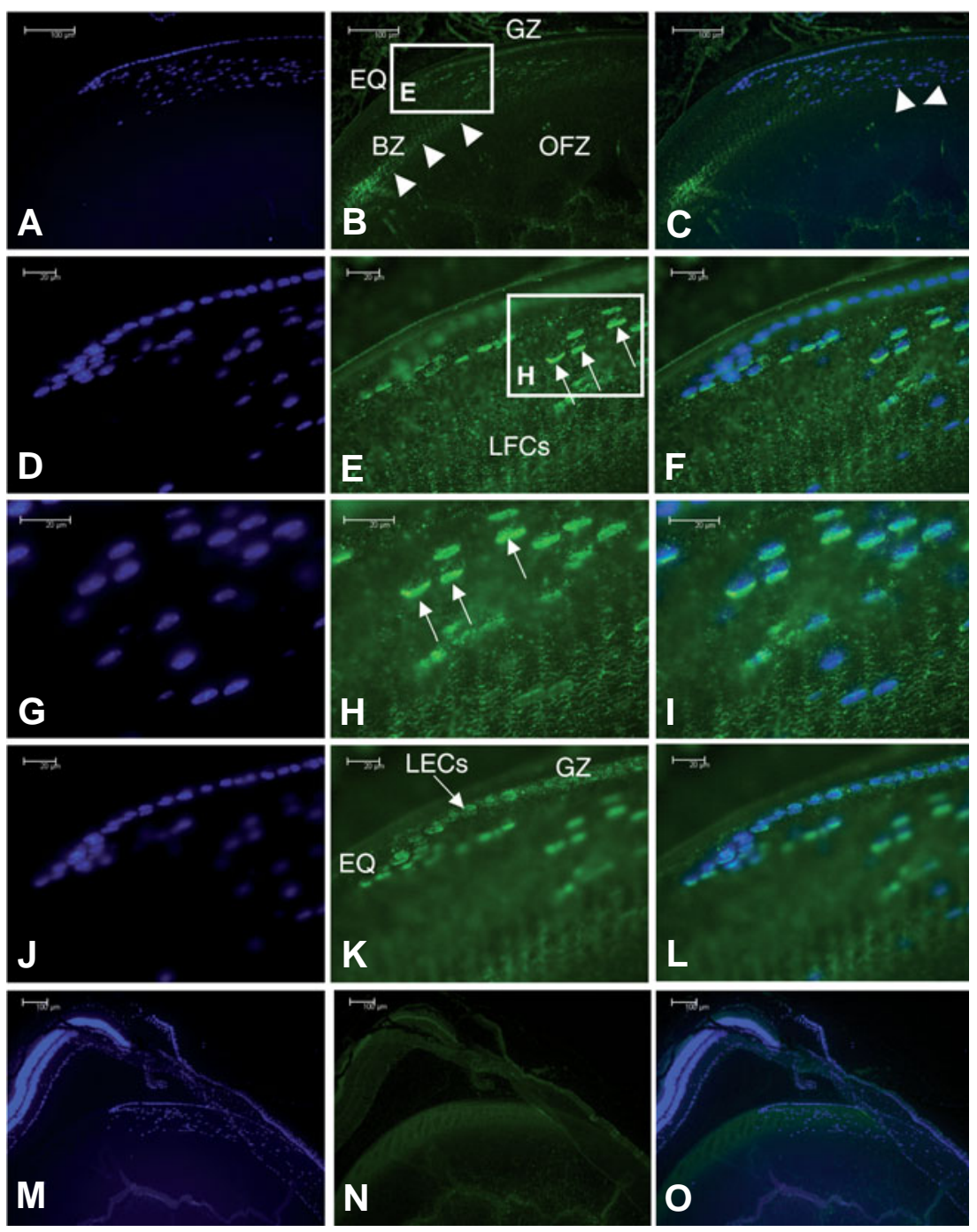

Fig. 8. Immunofluorescence for hemoglobin proteins, 9 wk mouse lens. (A,D,G,J,M) DAPI labelling. (B,E, $\mathbf{H}, \mathbf{K}, \mathbf{N})$ Hemoglobin immunofluorescence. (C, $\mathbf{F}, \mathbf{I}, \mathbf{L}, \mathbf{O})$ merged images. Regions defined by white rectangles in $(B)$ and $(E)$ are those in $(E)$ and $(H)$. Immunofluorescence is associated with LFCs at the boundary zone (BZ; arrowheads) (B,C) and with the surfaces of LFCs $(\mathbf{E}, \mathbf{F})$. Immunoflourescence is associated with a nuclearassociated sub-compartment (E, $\mathbf{F}, \mathbf{H}, \mathbf{I})$ in cortical LFCs. Immunofluorescence is also associated with the LECS $(\mathbf{K}, \mathbf{L})$. LEC staining is associated with the cytoplasm of LECs in the $G Z$, but becomes progressively more associated with nuclei of LECs approaching the lens equator (EQ) at which point $L E C$ s are differentiating into LFCs. (M-O) Sections stained with rabbit IgG at the same concentration as the hemoglobin antibody are negative for staining. Mag bars $100 \mu \mathrm{M}(\mathrm{A}-\mathrm{C} ; \mathrm{M}-\mathrm{O}) ; 20 \mu \mathrm{M}(\mathrm{D}-\mathrm{L})$. A laser scanning confocal microscopy movie (available at $h t t p: / / d x . d o i . o r g / 10.1387 / i j d b .082597 \mathrm{fm}$ ) taken from the same region of the lens as presented here is provided in the Supplemantary Information accompanying this paper online. whether EDDFs are also expressed in LFCs and have a role in LFC denucleation through their influence on hemoglobin expression.

Hypoxia is known to trigger apoptosis and, intriguingly in the context of the current data, oxygen levels within the developing chick lens can influence LFC denucleation/organelle loss. As new fiber cells bury existing LFCs during development, they are subjected to increasing hypoxia; in hyperoxic lenses, the organelle loss was triggered at a greater depth than under normoxic conditions (McNulty et al., 2004). We cannot totally exclude the possibil- ity that heme is present in the lens at undetectable levels, which are still sufficient to sense oxygen when associated with hemoglobin subunits. In any case, we suggest that the differentiation of LFCs is an ideal system with which to complete functional studies, given the lack of hematopoietic contamination.

\section{Expression of hemoglobin in villus epithelial cells}

Gut sections were stained in order to check for normal hemoglobin expression in erythrocytes from a highly vascularized 
tissue (as a positive control). Staining was noted, as expected, in anucleate erythrocytes, but also in rare, individual cells of the villus epithelium (Fig. 10). Stained epithelial cells were, as indicated by villus positioning, differentiating, migrating cells with nuclei (as indicated by DAPI staining). Stem cells are located in known positions in the crypts between villi, which give rise to daughter cells that mature, migrate, differentiate and are lost from the villus epithelium after approximately 7 days (Yen and Wright, 2006, Barker et al., 2007). Recent work has revealed hemoglobin expression in ATII cells; stem cells that differentiate into alveolar type I cells and Clara cells in the lung (Bhaskaran et al., 2005, Newton et al., 2006), supporting a wider role for hemoglobins in stem cell differentiation in general, in a manner consistent with the results presented here in early embryos and stem cells.

\section{RT-PCR and Western banding patterns and subunit stoichiometry}

With the exception of Hbb-Z, the hemoglobin subunit expression patterns we observed in the lens using RT-PCR differed markedly from those in blood (where expression of the embryonic $\mathrm{Hbb}-\mathrm{Y}$ and $\mathrm{Hba}-\mathrm{X}$ is down-regulated postnatally and is largely replaced by expression of $\mathrm{Hba}-1 / 2$ and $\mathrm{Hbb}-\mathrm{b} 1 /$ 2)(Lindenbaum and Grosveld, 1990). It is intriguing that "adult" hemoglobin subunits are expressed in the lens during embryonic development, while "embryonic" hemoglobin subunits continue to be expressed in the adult lens. The sizing of Western bands (Figs. 2 and 5 ) in the lens at different stages, blood and EBs were subtly different from each other (Figs. 2 and 5). It is possibile that monomers, dimers, trimers and even tetramers of hemo-
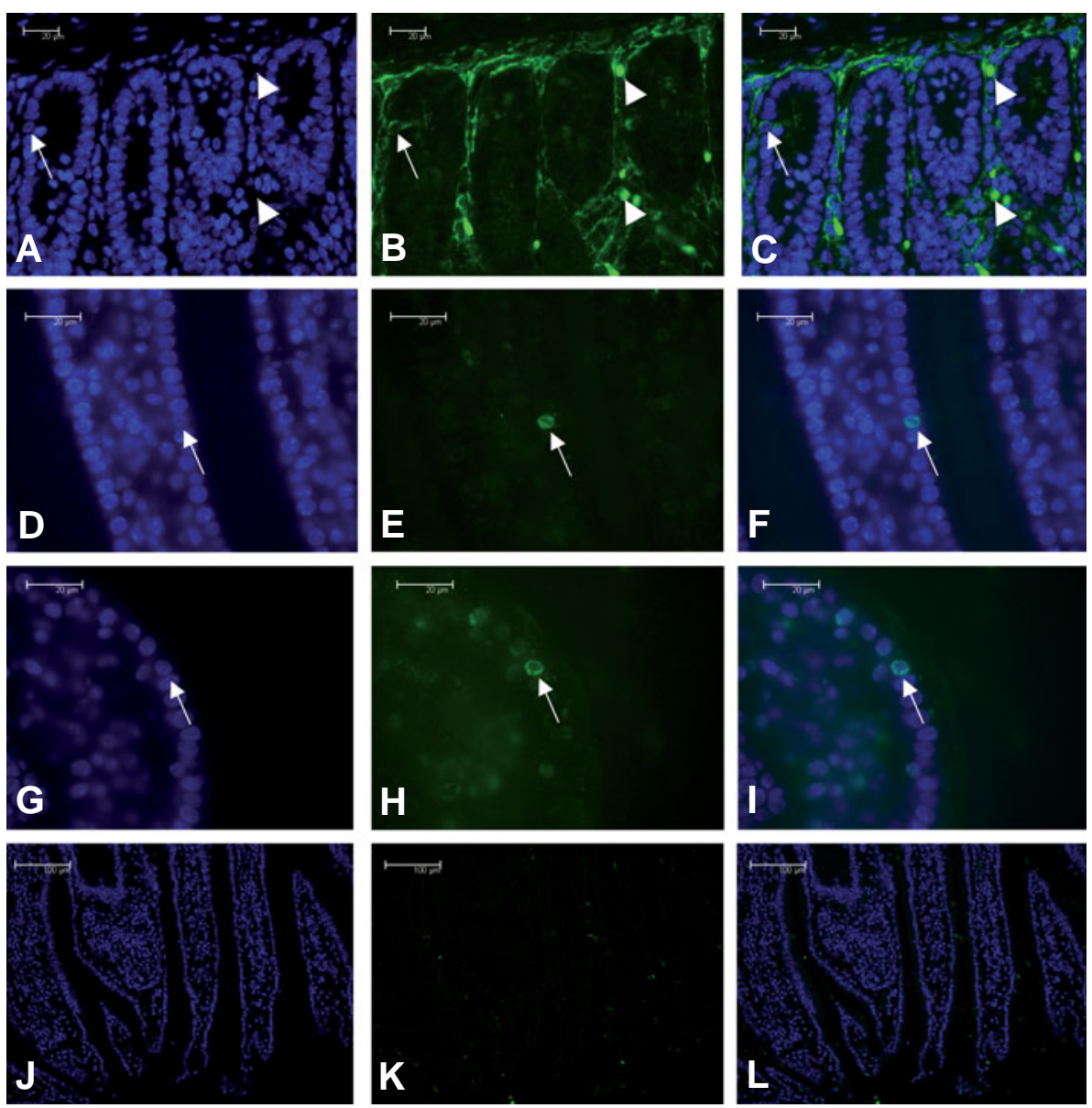

Fig. 10. Immunofluorescence for hemoglobin in adult mouse gut villus epithelium. (A,D,G,J) DAPl labelling. (B,E,H,K) Immunofluorescence. (C,F,I,L) Merged images. (A-C), (D-F) and (G-I) are three different sections stained with anti-mouse hemoglobin. In (A-C), hemoglobin immunofluorescence is associated with erythrocytes, identified by lack of DAPI nuclear staining in addition to the hemoglobin staining (arrowheads). Occasional individual nucleated cells of the gut villus epithelium are positive for hemoglobin immunoflourescence (arrows). (J-L) Sections stained with rabbit $\lg G$ at the same concentration as the hemoglobin antibody are negative for staining. Bars, $20 \mu \mathrm{M}(\mathrm{A}-\mathrm{I}) ; 100 \mu \mathrm{M}(\mathrm{J}-\mathrm{L})$. globin exist in EBs and the lens. The results also confirmed fetal globin protein expression in adult lenses.

It is possible that different combinations of hemoglobin subunits have different functional consequences. Neither possible splice variants of hemoglobin genes or post-translational modifi-

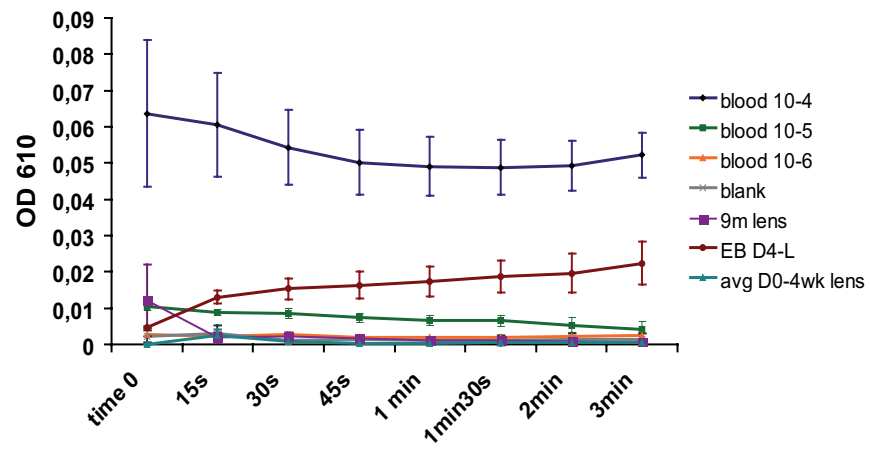

Time cations of hemoglobins have been investigated to date. However, "mix and match" combinations of hemoglobin protein subunits, differential splicing and posttranslational modifications could all explain banding pattern variation. Moreoever, polyacrylamide gel electrophoresis (PAGE) reducing conditions may not completely disassociate subunits from each other because of the electrostatic mechanisms by which they associate (Royer et al., 2001) and the different subunit interface strengths of embryonic, fetal, and adult hemoglobins (Manning et al., 2007). Notably, the usual tetrameric hemoglobin assembly is unlikely, at least in the lens, given the apparent absence of heme, while loss of hemoglobin subunit stoichiometry is thought to have functional consequences (Liu et al., 1999). Notably, Gata factors regulate hemoglobin

Fig. 9. Colorimetric difluoroacetate heme assay. OD610 versus time of reaction of the assay. Lens lysates (average of day 0 to $4 \mathrm{wk}$ lens lysate and 9 mo lens lysate) exhibit backround levels only (equivalent to the blank and blood lysate diluted at $10^{-6}$ ). The heme assay with EB lysates reveals the presence of the heme moiety. 
expression in the erythroid lineage and we have identified GATA binding protein 1 in the lens in our previous array studies (http:// watson-bios.grid.cf.ac.uk/array/), while Gata-3 is expressed in LFCs (Oosterwegel et al., 1992). However, it is likely that the process of transcriptional initiation in the lens is substantially different from that in erythrocytes.

\section{Eliminating hemoglobin contamination by erythrocytes}

We have taken multiple steps to ensure lack of erythrocyte contamination in the experiments described here. Lenses were carefully dissected free of any contaminating iris material (methods and lens pictures described previously)(Wride et al., 2003, Mansergh et al., 2004). Furthermore, mature erythrocytes, which comprise the vast majority of cells in circulation outside the bone marrow, lack nuclei, and therefore also lack substantial quantities of nucleic acid. This makes it relatively easy to avoid contamination at the PCR level. We also found persistent expression of fetal hemoglobin subunits in adult lenses; these genes are not expressed in the adult hematopoietic system. Hemoglobin protein contamination is a more noteworthy problem, but we would point to the fact that we could not detect any heme in adult lenses as an indication that these samples were not contaminated in any way; blood controls had to be diluted by $10^{-6}$ before heme was undetectable (see Fig. 9). The persistence of hemoglobin subunit protein in the central adult lens nucleus (obtained by removal of cortical LFCs and LECs), which has lost all nucleic acid, is also noteworthy. The results are similar to those with whole lenses, confirming that the bands detected are highly unlikely to be a consequence of erythrocyte contamination, since removal of the outer lens compartments would also remove any contaminating red blood cells from the iris and other adherent tissue invisible under the dissecting microscope. Finally, with regard to immunofluorescence, erythrocytes are immediately visible if present due to intense staining. Furthermore, slides were counterstained with DAPI to label DNA and erythrocytes are visible, especially on the gut sections, as cells staining bright green, but lacking nuclei.

\section{Concluding comments}

Hemoglobin subunits are expressed in the process of early differentiation from the stem cell population in various tissues (lens epithelium GZ, gut villi and lung) and in early embryogenesis (the blastocyst ICM and a stem cell model thereof; EBs). The expression of hemoglobin protein subunits (in the absence of heme) has been associated with apoptosis when over-expressed in various cell lines (Brecht et al., 2005a, Brecht et al., 2005b), while globin expression in LFCs and in erythroid cells is spatiotemporally associated with loss of nuclear DNA and other organelles (although the mechanism of loss differs). Moreover, apoptosis is a process intimately associated with early development and differentiation; therefore, hemoglobin subunits may be carrying out similar functions in early embryos and in differentiating cells of the lens, cornea and lung. The common theme between the embryo and the more mature tissues may be the extensive "remodeling" that these cells undergo as they differentiate. We propose that hemoglobin subunits (possibly without heme) have roles in development in apoptosis, nuclear degeneration/organelle loss and/or stem cell differentiation, in addition to their long-accepted roles in oxygen transport.

Further studies are now required to investigate novel function(s) of hemoglobin subunits in the development and differentiation of avascular tissues. We suspect that lower levels of non-oxygen transport related hemoglobin subunit expression outside of the hematopoietic system have been overlooked, owing to the difficulties of separating most tissues from their blood supply; nevertheless, secondary functions of hemoglobin may be common to most self-renewing tissues, and hence very important. Our future work will be directed towards determining the nature of these functions. The early embryo, ES cell differentiation in vitroand the avascular lens and cornea represent particularly useful model systems.

\section{Materials and Methods}

\section{Animal husbandry, tissue isolation}

Mice (129SvEv) were maintained under Home Office, U.K. license on a $12 \mathrm{~h}$ light/12 h dark light cycle with food and water ad libitum. Blood samples were obtained via decapitation immediately after cervical dislocation. Approx $250 \mathrm{ml}$ blood was dissolved in $750 \mathrm{ml} 1$ X RIPA buffer (Upstate), with 1 mini protease inhibitor tablet (Roche) per 10mls. Fetal blood samples were obtained from dissection of 16.5 embryos around the embryonic liver; a few microliters of blood were dissolved in RIPA buffer. Lenses were dissected from eyes by making a slit in the cornea, subsequent pressure on the sides of the eyeball resulted in extraction of the lens. Touching of the lens to clean tissue resulted in the removal of most excess adherent tissue, the remainder was dissected away using forceps under a dissecting microscope, in 1X PBS. Lens nuclei (cores) were obtained via the removal of the lens capsule and epithelium with forceps. Whole lenses and lens nuclei from 6 mice each were pooled and homogenized in mini-homogenizers (Fisher) in $1 \mathrm{ml} 1$ X RIPA buffer + protease inhibitor. Samples were chilled for 30 minutes, then spun at $13000 \mathrm{rpm}$ for 5 minutes at $4^{\circ} \mathrm{C}$ (Heraeus Picofuge). Supernatant was frozen at $-20^{\circ} \mathrm{C}$ in $250 \mathrm{ml}$ aliquots.

\section{Protein concentration assay}

Protein standards were prepared using serial BSA dilutions in $20 \mathrm{ml}$ water, containing $2 \mathrm{ml}$ of lysis buffer + protease inhibitors. Unknown samples were made up with $2 \mathrm{ml}$ cell extract plus $18 \mathrm{ml}$ water. The BioRad DC assay kit was used and OD750 readings taken (CamSpec) according to the manufacturers protocol.

\section{ES cell culture and differentiation}

Undifferentiated ES cells were maintained as previously described (Hunter et al., 2008) in MEM-Alpha (GibcoTM, Invitrogen Ltd, Paisley, Renfrewshire, UK) supplemented with mercaptoethanol (Merck KGaA, 64293 Darmstadt, Germany), 2mM glutamineb10-4 M and 10-3 U/ml murine LIF (ESGRO ${ }^{\text {TM }}$, Chemicon), 10\% FBS and 10\% NBS (selected batches, PAA Laboratories $\mathrm{GmbH}$, Linz, A-4020 Austria). The cells were maintained at $37^{\circ} \mathrm{C}$ in a humidified atmosphere with $5 \% \mathrm{CO} 2$ on $0.1 \%$ gelatin (Stem Cell Technologies) coated tissue culture grade plastic (NUNCTM, Fisher Scientific, Loughborough, Leics, UK). EBs were obtained from cell suspensions of trypsinized $(0.25 \%$ trypsin/EDTA, Invitrogen) undifferentiated ES cells. Hanging drops were assembled using standard protocols and 1000 cells per $10 \mathrm{ml}$ hanging drop, omitting the LIF from the medium. After 1 day of differentiation, EBs were flooded with $20 \mathrm{mls}$ of media -LIF. Growth was continued for a total of 4 days, RNA samples were extracted at each stage. Random EB cultures were generated as above, but allowing EBs to aggregate from $100 \mathrm{ES} \mathrm{cell} / \mathrm{ml}$ cell suspension, without hanging drops.

\section{Arrays}

Full methods for microarray analysis are available through GEO (GSE8881) and are also described elsewhere (Hunter et al., 2008). In brief, individual undifferentiated ES colonies were picked and embryonic 
sub-compartments were microdisected. 10-20 of each type were pooled, RNA was extracted using the Zymo Mini RNA isolation kit, amplified twice using the Arcturus RiboAmp kit (according to the manufacturer's protocols) and labeled using the Atlas ${ }^{\mathrm{TM}}$ PowerScript ${ }^{\mathrm{TM}}$ Fluorescent Labeling kit.

\section{RNA extraction, $R T$-PCR procedures, EB amplification}

RNA extraction, RT-PCR procedures and primers are as described previously (Wride et al., 2003, Mansergh et al., 2004, Hunter etal., 2008). Individual EBs were picked from two separate day 4- LIF cultures. 10 EBs were derived from hanging drop cultures (standard size), whereas 6 were derived from random aggregation (2 small, two medium and two large EBs). RNA extraction and one round of amplification were carried out (as per the array protocol), followed by DNase treatment (Turbo DNAfree kit, Ambion) and RT-PCR as above, but using random hexamers instead of oligo-dT.

\section{Tissue fixation and processing}

Whole E16.5 mouse embryos or enucleated post-natal or adult mouse eyes were fixed in $4 \%$ fresh paraformaldehyde in PBS overnight to $24 \mathrm{~h}$, washed in PBS and dehydrated through a graded series of ethanol before repeatedly soaking in 50:50 ethanol:xylene. After an overnight incubation, eyes were moved to xylene and washed twice, for $1 \mathrm{~h}$, then placed in hot wax for $2 \times 2 \mathrm{~h}\left(65^{\circ} \mathrm{C}\right)$. Eyes or embryos were embedded in paraffin wax and sectioned using a microtome (HM 325, Microm) at $7 \mu \mathrm{m}$. Sections were mounted on Histobond slides (Fisher Scientific).

\section{Immunohistochemistry and immunofluorescence}

Tissue sections were de-paraffinized in xylene and re-hydrated through a graded series of alcohols to distilled $\mathrm{H}_{2} \mathrm{O}$ prior to treatment with antigen unmasking solution (Vector Laboratories) according to the manufacturer's protocol. Slides were washed 3 times in PBS-T for 5 minutes each time, then quenched in a solution composed of $2.5 \mathrm{mls}$ hydrogen peroxide, 2.5 $\mathrm{mls}$ methanol, and $20 \mathrm{mls} d \mathrm{dH} 2 \mathrm{O}$. Further steps were carried out using the VectaStain Elite ABC kit (Vector Laboratories), according to the manufacturer's protocol, except that primary antibody incubations were carried out for 2 hours. Slides were incubated with one of 3 antihemoglobin primary antibodies as follows: Hemoglobin-b (H-76): sc21006 and Hemoglobin-a (H-80): sc21005 (both of which are anti-human and were used at a 1/50 dilution) as well as a rabbit anti-mouse hemoglobin antibody (ICN Biomedicals, cat no: 55447, diluted 1/400-1/800). Control rabbit IgG antibody (Sigma) was also used for each stage, concentrations were varied to match each of the antibodies tested. Slides were stained with the Vector Laboratories' VIP substrate kit for peroxidase. For immunofluorescence, the antigen retrieval and primary antibody incubation steps were carried out as above with antibodies at the same dilution, but an AlexaFluor-488 labeled secondary antibody (Invitrogen) was used instead. Slides were mounted in Vectashield Hardmount with DAPI (Vector Laboratories, UK) and photographed on a digital microscope (Leica DM4000/5000 B; Leica Microsystems Ltd, UK). We also carried out laser scanning confocal microscopy (TCS SP2 AOBS spectral confocal microscope system; Leica Microsystems Ltd, UK) and generated a movie through a section of the 9 wk lens cortex using Leica Confocal Software in order to highlight the nuclear-associated staining.

\section{PAGE and Western blotting}

Sodium dodecyl sulfate (SDS)-PAGE was carried out using the MiniProtean ${ }^{\circledR} 3$ cell system (Bio-Rad, UK) with $15 \%$ gels. $10 \mu \mathrm{g}$ of protein/ loading buffer mix was added to each well along with GE Healthcare Rainbow molecular weight markers. Proteins were transferred to a nitrocellulose membrane (Hybond ${ }^{\mathrm{TM}}$-P, Amersham Biosciences, UK). $5 \%$ milk/TBST was used for blocking; for some washes and antibody incubations. TBST washes alone were also used. A range of dilutions were used for optimization, the ICN/Cappel $\mathrm{Hb}$ antibody was used at 1/200-1/400 dilutions, the AbCam fetal antibody was used at $1 / 300$, while the human antibodies failed to recognize mouse hemoglobin subunits (including that from blood samples) at any concentrations tested (1/200-1/50 gave no result, while background was very high at $1 / 50)$. Secondary antibody solution (1\% milk and antibody at 1:2000) was added to the membrane for one hour at room temperature. Enzyme chemiluminescense (ECL) was used for detection (ECL Plus Western Blotting Detection Reagents, Amersham Biosciences, UK). Membranes were stripped and reprobed as necessary, a maximum of two times.

\section{Heme assay}

Heme detection was carried out using the diaminofluorene assay (Kaiho and Mizuno, 1985). Protocols for tissue, slide and lysate assay were derived directly from this paper. For histological staining of tissues sections and whole lenses for heme, $100 \mathrm{mg}$ diaminofluorene was dissolved in $10 \mathrm{ml}$ of $90 \%$ acetic acid $(10 \mathrm{mg} / \mathrm{ml})$ and tissues to be stained were prepared. $1 \mathrm{ml}$ of diaminofluorene/acetic acid solution was mixed with $100 \mathrm{ml}$ of $30 \%$ hydrogen peroxide and $10 \mathrm{ml}$ of $200 \mathrm{mM}$ Tris, $\mathrm{pH} 7.0$, containing $6 \mathrm{M}$ urea. This solution was added to whole lenses and corneas or deparaffinized sections for staining. Samples were incubated for 5 minutes at room temperature and photographed under a dissecting microscope as described previously (Mansergh et al., 2004). Tissue sections on slides were prepared and re-hydrated as for immunohistochemistry (described above), exposed to the above stain, and then dehydrated prior to mounting. For examination of heme in cell lysates, spectrophotometry was used. Blood and lens homogenates, as prepared for Western blotting (described above), were resuspended in $1 \mathrm{ml}$ of deionized $\mathrm{H}_{2} \mathrm{O}$. $10 \mathrm{mg} / \mathrm{ml}$ diaminofluorene solution was diluted to $5 \mathrm{mg} / \mathrm{ml}$ using more acetic acid. $100 \mathrm{ml}$ of the above solution was added to $10 \mathrm{mls}$ $100 \mathrm{mM}$ Tris, $\mathrm{pH} 7.0$, containing $6 \mathrm{M}$ urea. $1 \mathrm{ml}$ of this solution was mixed with $0.5 \mathrm{ml}$ cell extract in a disposable cuvette. The reaction was initiated via addition of $5 \mathrm{ul} 30 \%$ hydrogen peroxide. Changes in absorbance (OD610) were monitored at room temperature for 3 minutes (see Fig. 9 for intervals). The spectrophotometer (CamSpec) was blanked using deionized water plus all other components described above in the same proportions, but without any homogenate.

\section{Acknowledgments}

This work was funded by grants to MJE and MW from the Biotechnology and Biosciences Research Council (BBSRC), The Royal Society, the National Eye Research Centre (NERC), and the Medical Research Council (MRC) as well as the Higher Education Funding Council for Wales (HEFCW). FCM is currently supported by RP Ireland, Fighting Blindness. We would like to thank Dr Alicia Battersby for the gift of anti-sox2 antibody, Dr Karen Reed and Prof. Alan Clarke, Cardiff School of Biosciences for providing mouse small intestine slides and all three for constructive discussion of results. We would also like to thank Heather Phillips for technical assistance with histology and Llinos Williams for help with immunofluorescence and immunohistochemistry.

\section{References}

ATHANASIADIS, I., KONSTANTINIDIS, A., KYPRIANOU, I., ROBINSON, R., MOSCHOU, V. and KOUZI-KOLIAKOS, K. (2007). Rapidly progressing bilateral cataracts in a patient with beta thalassemia and pellagra. J Cataract Refract Surg 33: 1659-61

BABALOLA, O.E., DANBOYI, P. and ABIOSE, A.A. (2000). Hereditary congenital cataracts associated with sickle cell anaemia in a Nigerian family. Trop Doct 30 : $12-4$

BAIN, G., MANSERGH, F.C., WRIDE, M.A., HANCE, J.E., ISOGAWA, A., RANCOURT, S.L., RAY, W.J., YOSHIMURA, Y., TSUZUKI, T., GOTTLIEB, D.I. et al. (2000). ES cell neural differentiation reveals a substantial number of novel ESTs. Funct Integr Genomics 1: 127-39

BAIRD, J.W., RYAN, K.M., HAYES, I., HAMPSON, L., HEYWORTH, C.M., CLARK, A., WOOTTON, M., ANSELL, J.D., MENZEL, U., HOLE, N. et al. (2001). Differentiating embryonal stem cells are a rich source of haemopoietic gene 
products and suggest erythroid preconditioning of primitive haemopoietic stem cells. J Biol Chem 276: 9189-98

BARKER, N., VAN ES, J.H., KUIPERS, J., KUJALA, P., VAN DEN BORN, M., COZIJNSEN, M., HAEGEBARTH, A., KORVING, J., BEGTHEL, H., PETERS, P.J. et al. (2007). Identification of stem cells in small intestine and colon by marker gene Lgr5. Nature 449: 1003-7

BASSNETT, S. (2002). Lens organelle degradation. Exp Eye Res 74: 1-6

BHASKARAN, M., CHEN, H., CHEN, Z. and LIU, L. (2005). Hemoglobin is expressed in alveolar epithelial type II cells. Biochem Biophys Res Commun 333: 1348-52

BLISHCHENKO, E.Y., SAZONOVA, O.V., KALININA, O.A., YATSKIN, O.N., PHILIPPOVA, M.M., SUROVOY, A.Y., KARELIN, A.A. and IVANOV, V.T. (2002). Family of hemorphins: co-relations between amino acid sequences and effects in cell cultures. Peptides 23: 903-10

BLOOMFIELD, S.E., MARKENSON, A.L., MILLER, D.R. and PETERSON, C.M. (1978). Lens opacities in thalassemia. J Pediatr Ophthalmol Strabismus 15: 154-6

BRECHT, K., SIMONEN, M. and HEIM, J. (2005a). Upregulation of alpha globin promotes apoptotic cell death in the hematopoietic cell line FL5.12. Apoptosis 10: $1043-62$

BRECHT, K., SIMONEN, M., KAMKE, M. and HEIM, J. (2005b). Hematopoietic transcription factor GATA-2 promotes upregulation of alpha globin and cell death in FL5.12 cells. Apoptosis 10: 1063-78

DESBAILLETS, I., ZIEGLER, U., GROSCURTH, P. and GASSMANN, M. (2000). Embryoid bodies: an in vitro model of mouse embryogenesis. Exp Physio/85: 645-51

EVANS, M.J. and KAUFMAN, M.H. (1981). Establishment in culture of pluripotential cells from mouse embryos. Nature 292: 154-6

FRUITIER, I., GARREAU, I., LACROIX, A., CUPO, A. and PIOT, J.M. (1999). Proteolytic degradation of hemoglobin by endogenous lysosomal proteases gives rise to bioactive peptides: hemorphins. FEBS Lett 447: 81-6

GARROCHO-VILLEGAS, V., GOPALASUBRAMANIAM, S.K. and ARREDONDOPETER, R. (2007). Plant hemoglobins: what we know six decades after their discovery. Gene 398: 78-85

GARTAGANIS, S., ISMIRIDIS, K., PAPAGEORGIOU, O., BERATIS, N.G. and PAPANASTASIOU, D. (1989). Ocular abnormalities in patients with beta thalassemia. Am J Ophthalmo/ 108: 699-703

GEUENS, E., BROUNS, I., FLAMEZ, D., DEWILDE, S., TIMMERMANS, J.P. and MOENS, L. (2003). A globin in the nucleus! J Biol Chem 278: 30417-20

GRIEP, A.E. (2006). Cell cycle regulation in the developing lens. Semin Cell Dev Biol17: 686-97

HANKELN, T., EBNER, B., FUCHS, C., GERLACH, F., HABERKAMP, M., LAUFS, T.L., ROESNER, A., SCHMIDT, M., WEICH, B., WYSTUB, S. et al. (2005). Neuroglobin and cytoglobin in search of their role in the vertebrate globin family. $J$ Inorg Biochem 99: 110-9

HAWSE, J.R., HEJTMANCIK, J.F., HUANG, Q., SHEETS, N.L., HOSACK, D.A., LEMPICKI, R.A., HORWITZ, J. and KANTOROW, M. (2003). Identification and functional clustering of global gene expression differences between human age-related cataract and clear lenses. Mol Vis 9: 515-37

HOLE, N. (1999). Embryonic stem cell-derived haematopoiesis. Cells Tissues Organs 165: 181-9

HUNTER, S.M., MANSERGH, F.C. and EVANS, M.J. (2008). Optimization of minuscule samples for use with cDNA microarrays. JBiochem Biophys Methods 70: 1048-1058 (doi:10.1016/j.jprot.2007.11.011)

IANZER, D., KONNO, K., XAVIER, C.H., STOCKLIN, R., SANTOS, R.A., DE CAMARGO, A.C. and PIMENTA, D.C. (2006). Hemorphin and hemorphin-like peptides isolated from dog pancreas and sheep brain are able to potentiate bradykinin activity in vivo. Peptides 27: 2957-66

ITO, M. and YOSHIOKA, M. (1999). Regression of the hyaloid vessels and pupillary membrane of the mouse. Anat Embryol (Berl) 200: 403-11

KAIHO, S. and MIZUNO, K. (1985). Sensitive assay systems for detection of hemoglobin with 2,7-diaminofluorene: histochemistry and colorimetry for erythrodifferentiation. Anal Biochem 149: 117-20

KELLER, G., KENNEDY, M., PAPAYANNOPOULOU, T. and WILES, M.V. (1993). Hematopoietic commitment during embryonic stem cell differentiation in cul- ture. Mol Cel/ Biol 13: 473-86

KENNEDY, M., FIRPO, M., CHOI, K., WALL, C., ROBERTSON, S., KABRUN, N. and KELLER, G. (1997). A common precursor for primitive erythropoiesis and definitive haematopoiesis. Nature 386: 488-93

KOURY, M.J., BONDURANT, M.C. and ATKINSON, J.B. (1987). Erythropoietin control of terminal erythroid differentiation: maintenance of cell viability, production of hemoglobin, and development of the erythrocyte membrane. Blood Cel/s 13: $217-26$

KYBA, M., PERLINGEIRO, R.C. and DALEY, G.Q. (2002). HoxB4 confers definitive lymphoid-myeloid engraftment potential on embryonic stem cell and yolk sac hematopoietic progenitors. Cel/109: 29-37

LEAHY, A., XIONG, J.W., KUHNERT, F. and STUHLMANN, H. (1999). Use of developmental marker genes to define temporal and spatial patterns of differentiation during embryoid body formation. J Exp Zoo/284: 67-81

LINDENBAUM, M.H. and GROSVELD, F. (1990). An in vitro globin gene switching model based on differentiated embryonic stem cells. Genes Dev 4: 2075-85

LIU, L., ZENG, M. and STAMLER, J.S. (1999). Hemoglobin induction in mouse macrophages. Proc Nat/ Acad Sci USA 96: 6643-7

LOCKSHIN, R.A. and ZAKERI, Z. (2004). Caspase-independent cell death? Oncogene 23: 2766-73

LORENZEN, K., RAO, K.P., PATEL, A.R. and DESNICK, J. (1979). Sickle-cell anaemia and viscid aqueous humor associated with senile cataracts. Lancet 1 : 922-3

LOVICU, F.J. and ROBINSON, M.L. (2004). Development of the ocular lens. Cambridge University Press, Cambridge, UK,

MANNING, L.R., RUSSELL, J.E., PADOVAN, J.C., CHAIT, B.T., POPOWICZ, A., MANNING, R.S. and MANNING, J.M. (2007). Human embryonic, fetal, and adult hemoglobins have different subunit interface strengths. Correlation with lifespan in the red cell. Protein Sci16: 1641-58

MANSERGH, F.C., WRIDE, M.A., WALKER, V.E., ADAMS, S., HUNTER, S.M. and EVANS, M.J. (2004). Gene expression changes during cataract progression in Sparc null mice: differential regulation of mouse globins in the lens. Mol Vis 10: 490-511

MCNULTY, R., WANG, H., MATHIAS, R.T., ORTWERTH, B.J., TRUSCOTT, R.J. and BASSNETT, S. (2004). Regulation of tissue oxygen levels in the mammalian lens. J Physio/559: 883-98

NARDINI, M., PESCE, A., MILANI, M. and BOLOGNESI, M. (2007). Protein fold and structure in the truncated (2/2) globin family. Gene 398: 2-11

NEWTON, D.A., RAO, K.M., DLUHY, R.A. and BAATZ, J.E. (2006). Hemoglobin is expressed by alveolar epithelial cells. J Biol Chem 281: 5668-76

O'SHEA, K.S. (2004). Self-renewal vs. differentiation of mouse embryonic stem cells. Biol Reprod 71: 1755-65

OHYAGI, Y. and GOTO, I. (1994). Does iron-catalyzed oxidation of neuronal hemoglobin contribute to motor neuron degeneration? JNeuro/ Sci126: 237-9

OHYAGI, Y., YAMADA, T. and GOTO, I. (1994). Hemoglobin as a novel protein developmentally regulated in neurons. Brain Res 635: 323-7

OOSTERWEGEL, M., TIMMERMAN, J., LEIDEN, J. and CLEVERS, H. (1992). Expression of GATA-3 during lymphocyte differentiation and mouse embryogenesis. Dev Immuno/3: 1-11

PENDERGRASS, W., PENN, P., POSSIN, D. and WOLF, N. (2005). Accumulation of DNA, nuclear and mitochondrial debris, and ROS at sites of age-related cortical cataract in mice. Invest Ophthalmol Vis Sci 46: 4661-70

PERLINGEIRO, R.C., KYBA, M. and DALEY, G.Q. (2001). Clonal analysis of differentiating embryonic stem cells reveals a hematopoietic progenitor with primitive erythroid and adult lymphoid-myeloid potential. Development 128: 4597-604

PESCE, A., BOLOGNESI, M., BOCEDI, A., ASCENZI, P., DEWILDE, S., MOENS, L., HANKELN, T. and BURMESTER, T. (2002). Neuroglobin and cytoglobin. Fresh blood for the vertebrate globin family. EMBO Rep 3: 1146-51

ROYER, W.E., JR., KNAPP, J.E., STRAND, K. and HEASLET, H.A. (2001). Cooperative hemoglobins: conserved fold, diverse quaternary assemblies and allosteric mechanisms. Trends Biochem Sci26: 297-304

SCHMITT, R.M., BRUYNS, E. and SNODGRASS, H.R. (1991). Hematopoietic development of embryonic stem cells in vitro: cytokine and receptor gene expression. Genes Dev 5: 728-40 


\section{F.C. Mansergh et al.}

SEREGELYES, C., MUSTARDY, L., AYAYDIN, F., SASS, L., KOVACS, L., ENDRE, G., LUKACS, N., KOVACS, I., VASS, I., KISS, G.B. et al. (2000). Nuclear localization of a hypoxia-inducible novel non-symbiotic hemoglobin in cultured alfalfa cells. FEBS Lett 482: 125-30

SMITH, A.G. (2001). Embryo-derived stem cells: of mice and men. Annu Rev Cell Dev Bio/ 17: 435-62

SORCINELLI, R., SITZIA, A., FIGUS, A. and LAI, M.E. (1990). Ocular findings in beta-thalassemia. Metab Pediatr Syst Ophthalmo/13: 23-5

TASHEVA, E.S., KE, A., DENG, Y., JUN, C., TAKEMOTO, L.J., KOESTER, A. and CONRAD, G.W. (2004). Differentially expressed genes in the lens of mimecannull mice. Mol Vis 10: 403-16

VINOGRADOV, S.N., HOOGEWIJS, D., BAILLY, X., MIZUGUCHI, K., DEWILDE, S., MOENS, L. and VANFLETEREN, J.R. (2007). A model of globin evolution. Gene 398: 132-42

WILES, M.V. and KELLER, G. (1991). Multiple hematopoietic lineages develop from embryonic stem (ES) cells in culture. Development 111: 259-67

WRIDE, M.A. (2007). Proteases in the development and diseases of the lens.

\section{Expert Review of Ophthalmology 2: 833-844}

WRIDE, M.A., MANSERGH, F.C., ADAMS, S., EVERITT, R., MINNEMA, S.E., RANCOURT, D.E. and EVANS, M.J. (2003). Expression profiling and gene discovery in the mouse lens. Mol Vis 9: 360-96

XUE, S.P., ZHANG, S.F., MA, W., ZHANG, Z., LIU, P., ZHAO, Q. and HAN, D. (2006). Erythroid differentiation denucleation factors (EDDFs) function as intrinsic, post-erythropoietin regulators for mammalian erythroid terminal differentiation. Cell Prolif 39: 61-74

YEN, T.H. and WRIGHT, N.A. (2006). The gastrointestinal tract stem cell niche. Stem Cell Rev2: 203-12

ZHOU, M., LEIBERMAN, J., XU, J. and LAVKER, R.M. (2006). A hierarchy of proliferative cells exists in mouse lens epithelium: implications for lens maintenance. Invest Ophthalmol Vis Sci47: 2997-3003

ZIEGLER, B.L., VALTIERI, M., PORADA, G.A., DE MARIA, R., MULLER, R., MASELLA, B., GABBIANELLI, M., CASELLA, I., PELOSI, E., BOCK, T. et al. (1999). KDR receptor: a key marker defining hematopoietic stem cells. Science 285: 1553-8 


\section{Further Related Reading, published previously in the Int. J. Dev. Biol.}

See our recent Special Issue Eye Development edited by Joram Piatigorsky and Robert Grainger at: http://www.ijdb.ehu.es/web/contents.php?vol=48\&issue=8-9

See our recent Special Issue Ear Development edited by Fernando Giraldez and Bernd Fritzsch at: http://www.ijdb.ehu.es/web/contents.php?vol=51\&issue=6-7

Differentiation of human embryonic stem cells into hepatocytes in 2D and 3D culture systems in vitro Hossein Baharvand, Seyed M. Hashemi, Saeid Kazemi Ashtiani and Ali Farrokhi

Int. J. Dev. Biol. (2006) 50: 645-652

Embryonic development of the human hematopoietic system Manuela Tavian and Bruno Péault Int. J. Dev. Biol. (2005) 49: 243-250

Commitment of hematopoietic stem cells in avian and mammalian embryos: an ongoing story Françoise Dieterlen-Lièvre Int. J. Dev. Biol. (2005) 49: 125-130

Regulation of cell adhesion and migration in lens development Peggy S. Zelenka Int. J. Dev. Biol. (2004) 48: 857-865

Development of lens sutures Jer R. Kuszak, Rebecca K. Zoltoski and Clifford E. Tiedemann Int. J. Dev. Biol. (2004) 48: 889-902

A re-examination of lens induction in chicken embryos: in vitro studies of early tissue interactions Charles H. Sullivan, Leslie Braunstein, Royce M. Hazard-Leonards, Anna L. Holen, Fouad Samaha, Laurie Stephens and Robert M. Grainger

Int. J. Dev. Biol. (2004) 48: 771-782

\section{Congenital hereditary cataracts}

Jochen Graw

Int. J. Dev. Biol. (2004) 48: 1031-1044

Ocular surface epithelial and stem cell development J. Mario Wolosin, Murat T. Budak and M.A. Murat Akinci Int. J. Dev. Biol. (2004) 48: 981-991

Blind cavefish and heat shock protein chaperones: a novel role for hsp90alpha in lens apoptosis

Thomas A. Hooven, Yoshiyuki Yamamoto and William R. Jeffery

Int. J. Dev. Biol. (2004) 48: 731-738

Lens-specific activity of the chicken delta 1-crystallin enhancer in the mouse. Y Takahashi, K Hanaoka, K Goto and $\mathrm{H}$ Kondoh Int. J. Dev. Biol. (1994) 38: 365-368

The loss of gap junctional cell-to-cell communication is coupled with dedifferentiation of retinal pigmented epithelial cells in the course of transdifferentiation into the lens.

$R$ Kodama and G Eguchi

Int. J. Dev. Biol. (1994) 38: 357-364

Conversion of red blood cells (RBCs) from the larval to the adult type during metamorphosis in Xenopus: specific removal of mature larval-type RBCs by apoptosis.

Y Tamori and M Wakahara

Int. J. Dev. Biol. (2000) 44: 373-380 